Ana Claudia Venancio

\title{
Avaliação da viabilidade da técnica de acesso ao espaço epicárdico por punção transatrial
} para ablação epicárdica por cateter

\author{
Tese apresentada à Faculdade de Medicina da \\ Universidade de São Paulo para obtenção de título de \\ Doutor em Ciências
}

Programa de: Cardiologia

Orientador: Prof. Dr. Maurício Ibrahim Scanavacca

São Paulo

2010 
Dados Internacionais de Catalogação na Publicação (CIP)

Preparada pela Biblioteca da

Faculdade de Medicina da Universidade de São Paulo

Creprodução autorizada pelo autor

\section{Venancio, Ana Claudia}

Avaliação da viabilidade da técnica de acesso ao espaço epicárdico por punção transatrial para ablação epicárdica por cateter / Ana Claudia Venancio. -- São Paulo, 2010.

Tese(doutorado)--Faculdade de Medicina da Universidade de São Paulo. Programa de Cardiologia.

Orientador: Maurício Ibrahim Scanavacca.

Descritores: 1.Fibrilação atrial 2.Cateterismo cardíaco/métodos 3.Derrame pericárdico/terapia 4.Paracentese/métodos 5.Mapeamento epicárdico 6.Ablação por cateter 7.Suínos

USP/FM/DBD-445/10 
"Valeu a pena?

Tudo vale a pena se a alma não é pequena, quem quiser passar além do Bojador, tem que passar além da dor."

Fernando Pessoa.

\section{DEDICATÓRIA:}

À minha Família que faz tudo valer a pena.

E a Deus, que me justifica.

Our deepest fear is not that we are inadequate. Our deepest fear is that we are powerful beyond measure. It is our light, not our darkness, that most frightens us.

Your playing small does not serve the world. There is nothing enlightened about shrinking so that Other people won't feel insecure around you. We are all meant to shine as children do. It's not just in some of us; It is in everyone. And as we let our own lights shine, We unconsciously give other people permission to do the same. As we are liberated from our own fear, Our presence automatically liberates others. 


\section{AGRADECIMENTOS}

A meus pais que não me deram apenas a vida, mas a encheram de amor e significado.

A meus três irmãos, Maria Olinda, Aldo Márcio e Renata, que sempre estiveram e estarão ao meu lado, simplesmente por amor.

A meus avós, tios, cunhados e sobrinho, alguns que participaram apenas no início e partiram antes do fim, outros que chegaram até o final, ou nele como o Aldo Lucas, que fez com que houvesse alegria na continuidade.

Ao Dr. Rodrigo Nascimento, meu amigo, fiel, companheiro, por todas as idas à rodoviária e jantares felizes.

Ao Gil, por sua presença em minha vida há onze anos.

Aos meus pacientes, por sua compreensão em minhas muitas ausências.

Aos motoristas do ônibus leito, que durante 8 anos conduziram com segurança a minha vida, principalmente nos primeiros 5 anos em viagens semanais.

Ao Dr. Raul Sartini, que sem sua ajuda não teria iniciado meus projetos científicos.

Aos pacientes do ambulatório de fibrilação atrial do InCor, que acompanhamos semanalmente nos primeiros 3 anos.

À engenheira Helena Oyama, por todas as nossas discussões científicas e filosóficas, um gratificante exercício mental.

Ao departamento de Experimental, Sra. Edna Paola, e especialmente ao Sr. Richard, pelo excelente trabalho. 
Ao engenheiro Marcelo Mazzeto que juntamente com a Sra. Helena Oyama, desenvolveram o monitor de pressão positiva/negativa para este trabalho.

À Dra. Vera Aiello, por toda a ajuda e atenção, com seu imenso conhecimento e generosidade.

À Sra. Neuza e às secretárias da pós-graduação, por todas as orientações e soluções em todas as intercorrências.

À Sra. Valéria Lombardi, pela elaboração da ficha catalográfica e orientação no formato da tese.

Ao Prof. Eduardo Sosa e aos doutores Denise Hachul, Francisco Darrieux, Cristiano Pisani e Sissy Lara por todo o carinho, paciência, disponibilidade e auxílio para que houvesse uma integração ao departamento, ao Hospital, e se desenvolvessem e concluíssem os projetos.

Finalmente, ao Prof. Maurício Scanavacca pela oportunidade de ingressar na pós-graduação da Faculdade de Medicina da USP e por ter viabilizado a execução e conclusão deste trabalho. 
Esta tese está de acordo com as seguintes normas, em vigor no momento desta publicação:

Referências: adaptado de International Committee of Medical Journals Editors (Vancouver)

Universidade de São Paulo. Faculdade de Medicina. Serviço de Biblioteca e Documentação. Guia de apresentação de dissertações, teses e monografias. Elaborado por Anneliese Carneiro da Cunha, Maria Julia de A. L. Freddi, Maria F. Crestana, Marinalva de Souza Aragão, Suely Campos Cardoso, Valéria Vilhena. 2a ed. São Paulo: Serviço de Biblioteca e Documentação; 2005.

Abreviaturas dos títulos dos periódicos de acordo com List of Journals Indexed in Index Medicus. 


\section{SUMÁRIO:}

Lista de abreviaturas

Lista de símbolos

Lista de siglas

Resumo

Summary

1 INTRODUÇÃO

1.1 Mapeamento e ablação de fibras miocárdicas subepicárdicas para tratamento das arritmias cardíacas ............................................ 2

1.2 Mecanismos da fibrilação atrial ................................................. 2

1.3Estruturas subepicárdicas como substrato e alvo para ablação das taquicardias supraventriculares .................................................. 3

1.4 Ablação por cateter da fibrilação atrial .......................................... 5

1.5 Mapeamento e ablação epicárdica das taquicardias ventriculares ....... 11

1.6 Abordagens do espaço pericárdico para mapeamento e ablação de

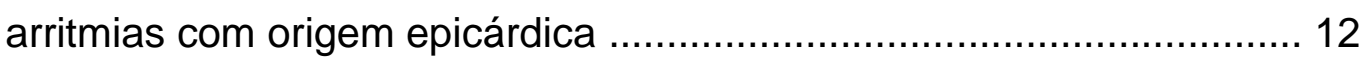

1.7 Acesso transatrial para o espaço pericárdico ................................ 13

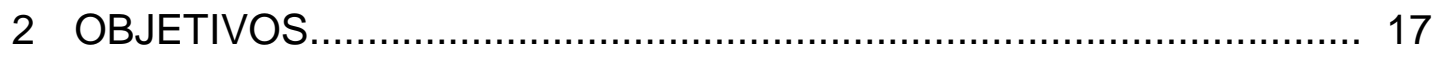

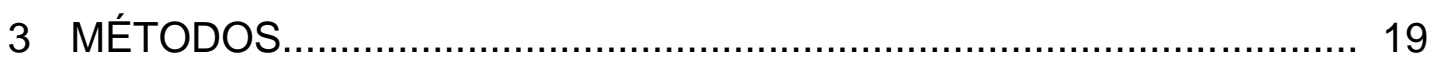

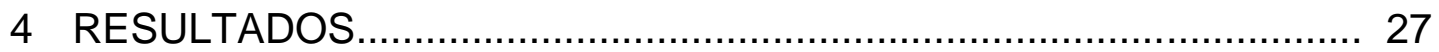

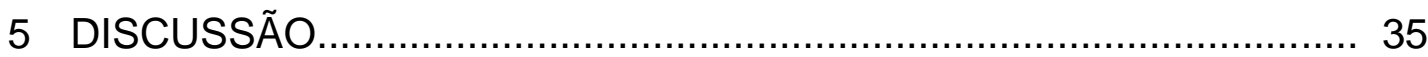

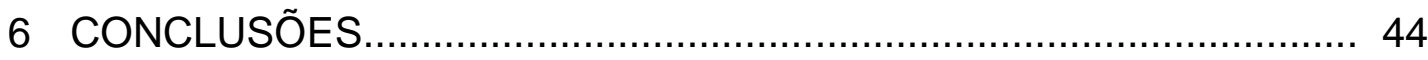

7 ANEXOS ............................................................................. 46

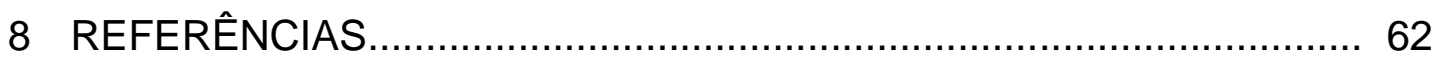




\section{Lista de abreviaturas}

AA drogas antiarrítmicas

AAD apêndice auricular ou atrial direito

$\mathrm{AE}$ átrio esquerdo

$A D$ átrio direito

Dr. doutor

ed. edição

et al. e outros

FA fibrilação atrial

FC frequência cardíaca

fig. figura

ICT istmo cavo-tricuspídeo

p. página

PA pressão arterial

Prof. professor

RAA right atrial appendage

RF radiofrequência

SC seio coronário

rev. revista

$\mathrm{RV}$ right ventricle

TV taquicardia ventricular

v. volume

VD ventrículo direito

VPs veias pulmonares 


\section{Lista de símbolos}

bpm batimentos por minuto

F French

Hz Hertz

IM intramuscular

IV intravenoso

$\mathrm{kg}$ quilograma

$\mathrm{mEq} / \mathrm{I}$ miliequivalente por litro

$\mathrm{mg} / \mathrm{kg}$ miligrama por quilo

$\mathrm{mg} / \mathrm{ml}$ miligrama por mililitro

min minuto

$\mathrm{ml} /$ animal mililitro por animal

$\mathrm{ml} /$ pig milimeters per pig

mm milímetro

mmHg milímetro de mercúrio

s segundo

vs. versus

W watt

${ }^{0} \mathrm{C}$ graus Celcius

$=$ igual $\mathrm{a}$

$>$ maior que

\pm mais ou menos

$<$ menor que

$\%$ por cento 


\section{Lista de siglas}

InCor Instituto do Coração da Universidade de São Paulo

HC-FMUSP Hospital das Clínicas da Faculdade de Medicina da

Universidade de São Paulo 


\section{Resumo}

Venancio AC. Avaliação da viabilidade da técnica de acesso ao espaço epicárdico por punção transatrial para ablação epicárdica por cateter [tese]. São Paulo: Faculdade de Medicina, Universidade de São Paulo; 2010. $75 p$.

Fundamentos - $\mathrm{O}$ acesso percutâneo ao espaço pericárdico pela via transatrial poderia ser uma alternativa ao acesso subxifóide para o mapeamento e ablação de fibras miocárdicas subepicárdicas. O objetivo deste estudo foi avaliar a viabilidade de alcançar o espaço pericárdico normal através do apêndice auricular direito (AAD) por acesso transvenoso. Métodos e Resultados - Um sistema Mullins (8F), originalmente desenvolvido para alcançar o átrio esquerdo $(\mathrm{AE})$ por punção transeptal foi utilizado neste estudo para transfixar o AAD (16) ou AE (1) em 17 suínos, com uma média de $26,9 \pm 2,6 \mathrm{~kg}$, e alcançar o espaço pericárdico normal. Um cateter 7F quadripolar com eletrodo distal com 4 ou $8 \mathrm{~mm}$ foi introduzido no espaço pericárdico para aplicações de radiofrequência. Em 15 (88\%) animais o procedimento foi realizado sem instabilidade hemodinâmica (PA média inicial $=80,4 \pm 11.7 \mathrm{mmHg} ;$ PA média final $=86,8 \pm 9.7 \mathrm{mmHg}, \mathrm{p}=$ $0,11)$. Foi identificado e aspirado derrame pericárdico discreto $(28,9 \pm 27.6$ $\mathrm{ml} /$ animal) durante o procedimento. O espaço pericárdico foi acidentalmente acessado por punção do ventrículo direito (VD) em um animal e por punção do anel da valva tricúspide em outro. Ambos apresentaram sangramento 
pericárdico importante e tamponamento cardíaco. Um dispositivo para oclusão do orifício de perfuração foi testado com sucesso em três porcos, dois no $A D$ e um no VD, sem ocorrência de derrame pericárdico significativo. Conclusões - $O$ acesso transatrial ao espaço pericárdico pode ser potencialmente útil para mapeamento e ablação de arritmias cardíacas, bem como para drenagem imediata de um tamponamento cardíaco agudo.

Descritores: 1.Fibrilação atrial 2.Cateterismo cardíaco/métodos 3.Derrame pericárdico/terapia 4.Paracentese/métodos 5.Mapeamento epicárdico 6.Ablação por cateter 7.Suínos 


\section{Summary}

Venancio AC. Percutaneous transatrial approach to reach the epicardial space for epicardial mapping and ablation [thesis]. São Paulo: "Faculdade de Medicina, Universidade de São Paulo"; 2010. 75p.

Background - A transvenous access to the pericardial space could provide a convenient route to map and ablate subepicardial myocardial fibers. The aim of this study was to evaluate the feasibility of reaching the normal pericardial space through the right atrial appendage (RAA) by transvenous access.

Methods and Results - An 8F Mullins system was used to transfix the right atrium (16) and left atrium (1) in 17 pigs with a mean of $26.9 \pm 2.6 \mathrm{~kg}$. A 7F quadripolar catheter with 4 or $8 \mathrm{~mm}$ distal tip electrode was introduced into the pericardial space to perform epicardial radiofrequency lesions. The pericardial space was successfully reached in 15 (88\%) animals without hemodynamic instability (initial mean BP $80.4 \pm 11.7 \mathrm{mmHg}$; final $86.8 \pm 9.7$ $\mathrm{mmHg}, \mathrm{p}=0,11)$. However, a mild pericardial serohemorrhagic effusion was identified and aspirated in all the animals $(28.9 \pm 27.6 \mathrm{ml} / \mathrm{pig})$ during the procedure. The pericardial space was accidentally accessed through the right ventricle $(\mathrm{RV})$ in one animal and through the tricuspid annulus in another, which presented important pericardial bleeding and cardiac tamponade. The hypothesis that an occlusion device could be useful to close the created atrial 
orifice was tested successfully in thee pigs (two at RAA and one at RV) and without significant pericardial bleeding.

Conclusions - The right atrial appendage route might be potentially useful to access the normal pericardial space for mapping and ablating cardiac arrhythmias as well as to drain promptly an acute tamponade.

Descriptors: 1.Atrial fibrillation 2. Heart catheterization/methods 3.Pericardial effusion/therapy 4.Paracentesis/methods 5.Epicardial mapping 6.Catheter ablation 7.Swine 
INTRODUÇÃO 


\section{Introdução}

\subsection{Mapeamento e ablação de fibras miocárdicas subepicárdicas para tratamento das arritmias cardíacas}

Apesar de ao longo dos anos haver reconhecimento da importância das fibras miocárdicas subepicárdicas como sítio de origem de várias taquicardias ventriculares e supraventriculares, poucas ferramentas específicas têm sido desenvolvidas para sua identificação precisa e tratamento mais efetivo.

\subsection{Mecanismos da fibrilação atrial}

As diferentes formas de apresentação clínica da fibrilação atrial (FA) sabe-se que se relacionam com diferenças importantes no mecanismo da FA. ${ }^{1-2}$ Enquanto a fibrilação atrial paroxística se apresenta dependente dos deflagradores onde se destacam as extrassístoles de veias pulmonares (VPs), a FA permanente, onde já não se consegue a reversão, relaciona-se com um importante remodelamento elétrico atrial.

A estrutura e os mecanismos da FA se baseiam numa composição entre mecanismos anatômicos e mecanismos arritmogênicos. ${ }^{3}$ Em uma visão posterior dos átrios pode-se observar a extensão das fibras musculares para dentro das VPs permitindo uma conexão elétrica destas com o átrio esquerdo. Existem quatro grandes plexos ganglionares 
autonômicos e seus axônios no átrio esquerdo (superior e inferior esquerdos e anterior e inferior direitos). Estes modulam a atividade parassimpática nos átrios levando a encurtamento dos períodos refratários e colaborando com o mecanismo de sustentação da FA.

O seio coronário encontra-se envolvido por fibras musculares que têm conexões com os átrios, assim como se tem a veia e o ligamento de Marshall, os quais caminham do seio coronário até a região entre o apêndice atrial esquerdo e a veia pulmonar superior esquerda. Essas conexões proporcionam vários caminhos de perpetuação do estímulo elétrico, onde ondas macro e micro reentrantes têm um participação no início e manutenção da FA. Os deflagradores podem apresentar origem em determinados locais fora das VPs, como as veias cavas e a veia e o ligamanto de Marshall.

Inúmeras novas variáveis têm sido investigadas quanto a provável fator de risco para FA, dentre elas destacamos a gordura pericárdica ${ }^{4}$, focos arritmogênicos $^{5-9}$ e estimulação simpática. ${ }^{10-11}$

\subsection{Estruturas subepicárdicas como substrato e alvo para ablação das taquicardias supraventriculares}

A abordagem epicárdica pode ter um papel importante na melhora dos resultados da ablação por cateter da FA. Um deles é a ablação de focos ectópicos extra-venosos como o ligamento de Marshal. A abordagem epicárdica é necessária para sua completa eliminação quando a abordagem 
endocárdica não é efetiva e o acesso da veia de Marshal não é tecnicamente possível. ${ }^{12}$ Outra possível aplicação da ablação epicárdica da FA é nas técnicas onde se busca um isolamento completo das veias pulmonares ou por meio do isolamento da parede posterior do átrio esquerdo, em especial em pacientes com FA persisitente e persistente prolongada, nas quais existe um remodelamento elétrico atrial importante. Entretanto, o isolamento de áreas extensas são tecnicamente difíceis devido à dificuldade em criar lesões lineares transmurais contínuas pela ablação endocárdica, mesmo quando se utilizam cateteres irrigados. A combinação da ablação pela superfície epicárdica ${ }^{13}$ pode ser necessária para a criação de lesões lineares transmurais definitivas.

A denervação autonômica do coração tem sido considerada no tratamento de pacientes com FA. Como a atividade vagal tem um papel na sustentação da FA, formulou-se a hipótese de que a denervação vagal, por meio da aplicação RF em áreas nas quais existe resposta vagal evocada, principalmente na superfície epicárdica dos átrios, poderia propiciar um maior sucesso às técnicas convencionais. ${ }^{14}$ Uma vez que os plexos autonômicos atriais estão localizados na superfície epicárdica dos átrios, em quatro áreas principais, próximo às veias pulmonares, Scanavacca et al avaliaram o efeito da ablação epicárdica dos gânglios autonômicos em pacientes com FA vagal. Embora tecnicamente exequível, o real benefício obtido por essas técnicas ainda foi limitado. ${ }^{15}$ Outros autores tiveram resultados contraditórios tentando promover a denervação vagal pela abordagem endocárdica. ${ }^{16-17}$ 
Schweikert et al demonstraram que a abordagem epicárdica pode ser útil em pacientes com taquicardias supraventriculares e falha de ablação endocárdica. ${ }^{18} \mathrm{Em}$ dez pacientes com vias acessórias que foram mapeadas pelo epicárdio e endocárdio, cinco tinham o local de maior precocidade da ativação ventricular na superfície epicárdica, sendo essa via eliminada com sucesso em três pacientes. Quatro pacientes com taquicardia sinusal inapropriada foram submetidos à mapeamento epicárdico, sendo evidenciado maior precocidade pelo epicárdio em dois, e um destes obteve sucesso com a ablação.

\subsection{Ablação por cateter da fibrilação atrial}

A FA é frequentemente refratária ao tratamento com drogas antiarrítmicas $(\mathrm{AA})$. Este fato motivou o desenvolvimento de técnicas não farmacológicas, cirúrgicas e por cateteres para tratamento mais efetivo da FA. ${ }^{19-23} \mathrm{~A}$ ablação por cateter com a utilização da energia de radiofrequência (RF) vem sendo aplicada de modo crescente nos últimos 15 anos, sendo recomendada nas diretrizes internacionais para tratamento de pacientes com FA sintomática, não controlada com o uso de pelo menos um fármaco antiarrítmico. ${ }^{24-25}$ Diante do diagnóstico de fibrilação atrial persistente ou permanente pode-se optar entre o tratamento com o controle do ritmo ou o tratamento com o controle da frequência. ${ }^{26-27}$

No estudo AFFIRM (Atrial Fibrillation Follow-up Investigation of Rhythm Management) foram comparados os resultados clínicos de "controle do 
ritmo" e "controle da frequência", em pacientes com idade média de 69,7 +/9 anos, com FA recorrente persistente ou permanente, obtendo-se resultados semelhantes. ${ }^{32}$ Porém a porcentagem de pacientes submetidos à ablação ou a implante de marcapasso ou desfibrilador, no controle do ritmo, foi muito pequena e estatisticamente insignificante. Assim, pode-se inferir que a ausência de diferença entre controle do ritmo e da frequência se aplica ao tratamento clínico para indivíduos acima de 65 anos, com frequência cardíaca controlada, sem dificuldade de anticoagulação ou manutenção do tratamento medicamentoso.

Várias técnicas de ablação por cateter foram sugeridas, sendo o isolamento elétrico das VPs reconhecido como um passo fundamental no procedimento, associado ou não à ablação de eletrogramas fracionados e à criação de linhas de bloqueio nos átrios.

A ablação com RF de focos ectópicos com origem nas VPs foi introduzida inicialmente na prática clínica para tratamento de pacientes com FA paroxística. ${ }^{28}$ Embora efetiva, esta técnica pode ser aplicada somente em uma minoria de pacientes com focos ectópicos muito ativos. Assim sendo, a ablação da FA paroxística se faz com o isolamento das VPs, sem indução e localização dos focos ectópicos deflagradores. ${ }^{29-30}$ Contudo, os resultados clínicos, e a necessidade de novas intervenções ainda são controversos. As limitações encontradas em pacientes com FA persistente e permanente estimularam a elaboração de técnicas mais efetivas que modificassem o substrato de manutenção da FA. 
Trabalho realizado pela equipe da Unidade de Arritmias e Marcapasso do InCor, mostra que o controle dos pacientes com FA paroxística após ablação por cateter chega a $80 \%{ }^{31}$ Hocini et al $\left.\right|^{32}$ evidenciaram que 0 isolamento das VPs é o objetivo da ablação de FA e tecnicamente executável em $100 \%$ dos casos associando-se a $70 \%$ de sucesso, assim como apresentaram as modificações técnicas sugeridas pelo grupo para 0 isolamento das VPs. Esta ablação tem sido realizada com lesões circunferenciais a aproximadamente um $\mathrm{cm}$ fora dos óstios das VPs. Adicionalmente, as regiões do antrum das VPs com eletrogramas de dois ou mais componentes também são ablacionadas. ${ }^{33} \mathrm{~A}$ avaliação de 368 pacientes consecutivos submetidos a esta técnica, mostrou que $69 \%$ deles permaneceram sem recorrência e sem AA em seguimento médio de $10 \pm 5$ meses. $^{34}$

No InCor, após um seguimento de $33 \pm 12$ meses, observou-se que maior tempo de história de $F A$, uso de mais $A A$ e recorrência de FA num período de sessenta dias pós-procedimento aumentaram o risco de recorrência de FA em longo prazo. Por sua vez, a associação de flutter atrial e a ablação concomitante do istmo cavo-tricuspídeo (ICT) reduziram o risco de recorrência. Variáveis clínicas como tempo de história de FA e maior quantidade de AA já utilizada influenciaram os resultados da ablação por cateter. Em pacientes com flutter atrial associado, a realização concomitante de linha de bloqueio no ICT reduziu significativamente a recorrência de fibrilação atrial a longo prazo. ${ }^{35}$ 
A Sociedade Brasileira de Cardiologia recomenda sua realização em pacientes com FA paroxística, sintomática e de difícil controle farmacológico, com átrio esquerdo normal e na ausência de condições metabólicas potencialmente correlacionadas à arritmia (Recomendação B2, Nível 3); e nos pacientes com FA paroxística e frequente, de difícil controle farmacológico, com cardiopatia estrutural (Recomendação B2, Nível 4). ${ }^{25}$

No InCor as indicações para ablação da FA vêm se modificando com a experiência obtida pelo grupo no decorrer dos últimos anos. Atualmente são candidatos os pacientes com FA paroxística ou persistente, sintomática, com evolução mínima de seis meses, refratária a pelo menos duas $A A$, tendo sido afastadas condições potencialmente deflagradoras como hipertireoidismo e consumo excessivo de álcool. Evita-se a indicação em pacientes com limitações para uso de anticoagulante oral.

Nos pacientes com FA persistente ou permanente, sugere-se que duas linhas de bloqueio sejam realizadas no átrio esquerdo, além do isolamento das VPs. Uma delas ligando a veia pulmonar inferior esquerda ao anel mitral e a outra ligando as duas VPs superiores. Aplicando-se esta estratégia, 87\% dos pacientes com FA paroxística e 70\% dos pacientes com FA persistente estavam livres de taquiarritmias atriais sem $\mathrm{AA}$, em seguimento médio de um ano. $^{36}$

Alguns eletrofisiologistas e cirurgiões cardíacos acreditam que os melhores resultados serão obtidos quando se produzir lesões transmurais bipolares na construção do quadrado da cirurgia de Maze. ${ }^{37-39} \mathrm{~A}$ a estratégia de reprodução da cirurgia do labirinto por cateter foi retomada, atualmente 
realizada com sistema de mapeamento computadorizado com reconstrução tridimensional ${ }^{40}$ das câmaras atriais e a ablação com equipamentos de RF capazes de produzir lesões mais profundas e transmurais. ${ }^{41-45}$ Lesões mais extensas nos antros das VPs provocam mudança no substrato de manutenção da FA e denervação autonômica do átrio esquerdo, com resultados aparentemente mais satisfatórios no controle da FA. ${ }^{46-47}$

O registro brasileiro de ablação de FA em 2007 evidenciou taxa de sucesso de $82 \%$ com drogas antiarrítmicas e de $35 \%$ de reintervenção. ${ }^{48}$

A taxa de manutenção do isolamento elétrico das VPs é aparentemente maior quando realizada durante procedimentos cirúrgicos, utilizando equipamentos com alta probabilidade de obter lesão transmural linear (ablação com RF bipolar). Esta observação estimulou alguns eletrofisiologistas associar aplicações epicárdicas às endocárdicas. ${ }^{49}$ Assim, melhores técnicas têm sido pesquisadas para que se obtenha uma ablação segura, eficaz e que promova um isolamento das veias pulmonares, com a criação de lesões lineares transmurais permanentes. ${ }^{50-52}$

Outro aspecto que merece atenção, é que apesar de todo avanço técnico e tecnológico obtido nos últimos anos, a ablação por cateter da FA ainda continua complexa e requer punção transeptal para acessar o átrio esquerdo. A técnica de punção transeptal modificou-se muito pouco ao longo dos anos, apresentando somente pequenas variações incorporadas por alguns operadores, objetivando ampliar a segurança do procedimento.

$\mathrm{Na}$ maioria dos centros, realiza-se a punção transeptal guiada exclusivamente pela radioscopia, entretanto, ecocardiografia intracardíaca 
ou transesofágica podem ser utilizadas para execução de punção mais segura em casos específicos. O tamponamento cardíaco pode ocorrer, apesar de todas as precauções, em 0,1 a $2,4 \%$ dos pacientes. Ocorre devido à perfuração da parede atrial até mesmo em serviços experientes, com ou sem orientação ecocardiográfica, e é potencialmente fatal se não reconhecido e tratado precocemente..$^{53-56}$

O tamponamento é uma complicação maior dos procedimentos ablativos em átrio esquerdo e resulta, na maioria dos casos, de sangramento intrapericárdico agudo devido à perfuração atrial relacionada à punção transeptal, manipulação de cateter ou aplicação de alta potência de energia nas câmaras atriais. De todas as 32 complicações fatais (1 para cada 1000 pacientes) observadas em uma série de 45.115 procedimentos em 32.569 pacientes, o tamponamento foi a causa mais frequente e ocorreu em 8 pacientes. ${ }^{57}$

A pericardiocentese através da punção subxifóide ${ }^{58}$ percutânea quando realizada precocemente é efetiva no tratamento de tamponamento cardíaco, entretanto, anticoagulação deve ser revertida e a ablação interrompida na maioria dos casos. ${ }^{59-60}$ Além disso, alguns pacientes com sangramento persistente podem necessitar de correção cirúrgica a céu aberto.

Situação que pode ocorrer durante o procedimento, potencialmente letal é quando a punção subxifóide não pode ser obtida ou por dificuldade de acesso subxifóide ou pela presença de hematoma com coágulos junto ao ventrículo direito mais grave ocorre quando a punção subxifóide não é obtida levando a parada cardíaca por tamponamento cardíaco. Haissaguerre et al 
descreveram um caso onde a punção subxifóide não pode ser obtida, e buscando alternativa na punção trancardíaca, que foi efetiva nesse caso para promover a drenagem pericárdica e aliviar o tamponamento cardíaco, salvando a vida do paciente.$^{61}$ Entretanto, sugeriu que a retirada da bainha transfixando a parede atrial ou ventricular deveria ser realizada em ambiente cirúrgico para correção da perfuração.

\subsection{Mapeamento e ablação epicárdica das taquicardias ventriculares}

A ablação por cateter das taquicardias ventriculares (TVs) é habitualmente um procedimento trabalhoso e às vezes pouco efetivo, dada a complexidade de organização do circuito reentrante, o mecanismo mais comum destas taquicardias. Este fato torna difícil a identificação e eliminação de todas as vias envolvidas na sua sustentação, principalmente quando estas estão relacionadas com fibras miocárdicas subepicárdicas. Por este motivo, diversas estratégias vêm sendo implementadas para mapeamento e ablação das TVs. Uma delas é o acesso percutâneo do espaço pericárdico para investigar possível origem subepicárdica de uma determinada TV. ${ }^{62}$ 


\subsection{Abordagens do espaço pericárdico para mapeamento e ablação de arritmias com origem epicárdica}

Atualmente, o mapeamento epicárdico extenso pode ser realizado por técnicas cirúrgicas e não cirúrgicas. As técnicas cirúrgicas incluem o acesso direto com o tórax aberto ou por instrumentação toracoscópica. ${ }^{63}$ Embora ambas as técnicas possam ser realizadas no laboratório de eletrofisiologia, requerem a assistência de um cirurgião. O seio coronário e a grande veia cardíaca têm sido explorados durante estudo eletrofisiológico convencional, com cateteres regulares. No entanto, microcateteres especiais podem ser necessários para explorar os ramos coronarianos mais distais. ${ }^{64}$

A abordagem subxifóide percutânea permite mapeamento amplo da superfície epicárdica do coração. Sosa et al ${ }^{65}$ demonstraram que a ablação epicárdica utilizando punção pericárdica subxifóide é uma técnica segura e eficaz em ablação de taquicardia ventricular. ${ }^{66-70}$ Durante os últimos 14 anos, desde a descrição da técnica em 1996, não houve grandes desenvolvimentos na técnica ou em materiais para auxiliar sua execução. A despeito da ausência de instrumentos específicos para sua realização, a punção subxifóide com a agulha de Tuhoy (desenvolvida para acesso ao espaço epidural) apresenta taxa de sucesso acima de $95 \% .^{71-72}$

Entretanto, devido ao alvo da punção ser um espaço virtual, existe o risco de ultrapassar a superfície visceral do pericárdio levando à lesão da parede livre do ventrículo direito e à ocorrência de sangramento intrapericárdico. Sosa e Scanavacca descreveram em uma série de 257 
procedimentos consecutivos realizados no Instituto do Coração (InCor/HCFMUSP), que acidentes de punção ocorreram em até $15 \%$ dos pacientes, mas a interrupção do procedimento, em geral, não é necessária. Em torno de $1 \%$ dos casos, o acidente de punção resulta em sangramento persistente sendo necessária toracotomia para correção ${ }^{68} \mathrm{O}$ risco de punção acidental nas diversas publicações varia de 10 a $20 \%$, sendo que na maioria das vezes é discreto e sem repercussão importante.

Em 373 pacientes submetidos à ablação epicárdica de taquicardia ventricular no InCor, 5\% tiveram punção de ventrículo direito, 10\% drenagem

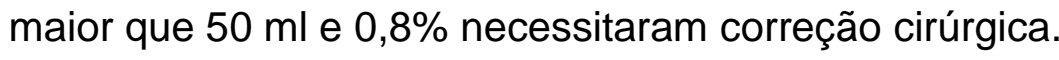

Em registro multicêntrico, envolvendo 913 procedimentos de ablação de TV, relacionados, em sua maioria (87\%) com o substrato cicatricial, foi observado que 156 pacientes necessitaram mapeamento e ablação epicárdica. ${ }^{54}$ Complicações agudas relacionadas a esta abordagem foram descritas em oito (5\%) pacientes. Destas, sete foram hemopericárdio $\left(>80 \mathrm{~cm}^{3}\right)$.

\subsection{Acesso transatrial para o espaço pericárdico}

Verrier et al $^{73}$ demonstraram que a abordagem percutânea via apêndice atrial direito $(A A D)$ é uma rota transvenosa rápida e segura para acessar o espaço pericárdico normal. Estudos posteriores confirmaram que o acesso transatrial do espaço pericárdico pode ser útil para uma série de modalidades terapêuticas que vão desde a infusão de drogas no espaço 
pericárdico ${ }^{74-77}$ até 0 implante de eletrodos epicárdicos para estimulação cardíaca artificial, incluindo para a terapia de ressincronização cardíaca. ${ }^{78-80}$ Recentemente, Scanavacca et $\mathrm{a}^{81}$ observaram, em dois pacientes que apresentaram perfuração acidental da parede posterior do átrio esquerdo, com introdução da bainha transeptal no espaço pericárdico, que a redução progressiva do calibre do cateter transfixante, associada à pressão negativa no espaço intrapericárdico possibilitou a remoção dos cateteres sem a formação de hemopericárdio importante ou tamponamento cardíaco.

Considerando as diferentes indicações de acesso epicárdico nos procedimentos de ablação de FA e buscando uma melhora no resultado da ablação, uma combinação das abordagens endocárdica e epicárdica poderia ser mais efetiva. A punção pericárdica transatrial também poderia ser uma opção intravascular mais rápida e confortável ao eletrofisiologista, para realização de pericardiocentese durante tamponamento cardíaco.

$\mathrm{Na}$ presença de orifício transatrial ou transventricular, pela punção ou acidental, esse poderia ser ocluído por pressão negativa ou utilização de prótese percutânea existente ou a ser desenvolvida especificamente para oclusão de comunicação com espaço pericádico.

Existem várias descrições de oclusão de orifícios interatriais e interventriculares por diferentes próteses percutâneas com sucesso e sem maiores intercorrências. ${ }^{82-88}$ Porém, não existem próteses disponíveis específicas para utilização em oclusão de orifícios transmurais ao espaço pericárdico. 
Após essas considerações, acreditamos que o acesso transatrial ao espaço pericárdico pode ser uma alternativa à abordagem subxifóide para mapeamento e ablação de arritmias cardíacas, assim como para correção rápida e não cirúrgica de acidentes de punção e drenagem de hemopericárdico. 
OBJETIVOS 


\section{Objetivos}

O objetivo primário deste estudo foi avaliar a exequibilidade e a segurança da técnica de abordagem por punção transatrial do espaço pericárdico, para mapeamento e ablação epicárdica, em experimento animal.

O objetivo secundário foi avaliar se a utilização de um sistema de oclusão de orifícios interatriais adiciona segurança na retirada das bainhas do espaço pericárdico. 
MÉTODOS 


\section{Métodos}

Os experimentos foram realizados de acordo com protocolo aprovado pelo comitê científico de ética em pesquisa e de acordo com diretrizes de boas práticas para o cuidado de animais de laboratório. ${ }^{89}$

A técnica de punção transatrial foi estudada em 20 animais suínos, raça Landrace, de Procedência da Granja JA Agropecuária, Holambra, São Paulo. Os suínos foram escolhidos por apresentarem a espessura do pericárdio e da parede atrial mais semelhante à do homem, com seu peso entre 23 e 40 kg (Média $27.9 \pm 3.8 \mathrm{~kg}$ ).

Estando em jejum alimentar na noite anterior ao procedimento, os animais foram sedados com cloridrato de quetamina (22 $\mathrm{mg} / \mathrm{kg}-\mathrm{IM})$ e midazolam $(0.3 \mathrm{mg} / \mathrm{kg}-\mathrm{IM})$ intramusculares, seguindo o peso informado pelo fornecedor. ${ }^{89}$ Depois de sedados, o peso foi confirmado e os animais encaminhados à sala cirúrgica.

O acesso venoso periférico foi obtido em região auricular dos animais, com abocath individualizado para cada animal. Anestesia geral foi induzida pela equipe de anestesia com thionembutal intravenoso (IV) na dose de 10 $\mathrm{mg} / \mathrm{kg}$, seguido de halotano ou isoflurane inalatório a $1 \%$ por intubação orotraqueal, em ventilação mecânica (equipamento TAKAOKA - Modelo 201010022 / SN: 3190).

Os animais foram monitorizados continuamente durante o procedimento por eletrocardiografia por monitor cardíaco e cardio-desfibrilador HewlettPackard (CodeMaster XL). 
A medida de pressão arterial invasiva foi realizada através de cateterismo da artéria femoral direita, após dissecção da mesma. Então foram realizadas duas punções venosas, a primeira após ressecção do músculo adutor e dissecção da veia femoral direita e a segunda por punção direta da pré-cava, correspondente a veia cava superior e que se situa medial à artéria carótida.

Nos acessos venosos foram colocados introdutores $7 \mathrm{~F}$ e $8 \mathrm{~F}$, para posterior avanço dos eletrocateteres. No acesso venoso superior, pela précava, foi introduzido cateter decapolar deflectível 7F para o interior do seio coronário. Pelo acesso venoso femoral direito, inicialmente se introduziu um cateter quadripolar 7F para mapeamento do feixe de His, realizando-se assim os registros de His e seio coronário. (Figura 1)

O objetivo destes registros endocavitários consistiu em determinar as relações anatômicas entre His, seio coronário e a posição anatômica do apêndice auricular direito (AAD).

Os eletrogramas intracardíacos foram registrados utilizando sistema de eletrofisiologia multicanal (EP Tracer Cardiotek, Maastricht, the Netherlands), com filtros de banda entre 80 e $500 \mathrm{~Hz}$, com demonstração simultânea na tela das derivações periféricas (DI, DII, DIII, aVR, aVL e aVF) e dos eletrogramas bipolares adquiridos através dos cateteres de eletrofisiologia. As imagens radioscópicas foram obtidas e gravadas através de sistema de fluoroscopia marca Philips (ON:01J0FH157 / SN: 000276).

Após estes registros o cateter quadripolar foi retirado, e por este acesso se avançou a bainha de Mullins 8F, através do fio guia. Uma vez 
posicionada a bainha na face lateral do atrial direito (AD), retirou-se o dilatador e o guia. Introduziu-se novamente um cateter quadripolar 7F, agora pela bainha de Mullins, para mapeamento da cavidade e registro do eletrograma atrial e posicionamento da bainha na face anterior do AAD. (Figura 2)

Retirado o cateter, procedeu-se a injeção de $5 \mathrm{ml}$ de contraste (loxaglato de meglumina $320 \mathrm{mg} / \mathrm{ml}$ ) diluído em $5 \mathrm{ml}$ de solução fisiológica a 0,9\% para a realização da atriografia. (Figura 3)

A punção transatrial para acesso ao espaço pericárdico foi realizada com o avanço do guia $(0,32$ ou $0,35 \mathrm{~mm})$ e do dilatador até que a ponta do sistema atingisse o AAD. O dilatador foi lentamente pressionado contra 0 AAD e o fio guia foi avançado através do dilatador a fim de perfurar o AAD para atingir o espaço pericárdico. (Figura 4)

A agulha para acesso transeptal de Brokenbrough foi reservada para realizar a punção epicárdica transatrial apenas quando o avanço do guia e do dilatador não fosse eficaz para acessar o espaço pericárdico.

Após a punção, o fio guia foi avançado até que o mesmo fosse visualizado ao redor da silhueta cardíaca (Figura 5), o que confirma o seu posicionamento no espaço pericárdico. A bainha e o dilatador foram avançados no espaço pericárdico sobre o fio guia e após a confirmação radioscópica da bainha no espaço pericárdico, o fio guia e o dilatador foram retirados. A seguir foi realizada infusão de pequena quantidade de contraste para nova confirmação da bainha no espaço pericárdico, seguidos de 
aspiração através da bainha do conteúdo do espaço pericárdico para avaliação inicial de presença de hemopericárdio.

A possibilidade do acesso transatrial foi testada em 17 animais, em 16 através do AAD e um através do apêndice atrial esquerdo. Em outros três animais foi avaliada a segurança da utilização de dispositivos de oclusão do orifício gerado para acesso.

Após o sucesso no acesso, um cateter de ablação $4 \mathrm{~mm}$ ou $8 \mathrm{~mm}$ foi colocado no espaço pericárdico para mapeamento e ablação (Figura 6). O mapeamento epicárdico foi simulado com o posicionamento do cateter epicárdico em várias áreas do ventrículo direito, ventrículo esquerdo, átrio direito e átrio esquerdo. A pressão arterial foi continuamente monitorizada e a silhueta cardíaca periodicamente visualizada a fim de identificar possível hemopericárdio.

Foram realizadas aplicações de radiofrequência nos átrios esquerdo e direito, com controle de potência e temperatura, guiadas pela radioscopia e eletrogramas, sendo realizados pulsos de RF (gerador Irvine 1500 T), de 50 $\mathrm{W}, 60^{\circ} \mathrm{C}$ e por 60 segundos. Ao término das aplicações se removeu o cateter do espaço pericárdico. Introduziu-se um cateter angiográfico multiperfurado "pig-tail" 6F para a exploração das diversas partes do espaço pericárdico a fim de identificar e drenar eventual sangramento. Se algum derrame fosse identificado, era removido através da aspiração do cateter "pig-tail" e quantificado.

Após 30 minutos da drenagem total de eventual sangramento e da remoção da bainha de Mullins para o interior do $A D$, manteve-se por 15 
minutos uma pressão negativa por aspiração contínua no cateter "pig-tail" do espaço pericárdico. Para a manutenção e monitorização da pressão negativa foi utilizado sistema de medição de pressão, o monitor de pressão positiva/negativa com faixa de medida de $+/-500 \mathrm{mmHg}$, com resolução de $1 \mathrm{mmHg}$, desenvolvido pela Divisão de Bioengenharia / Centro de Tecnologia Biomédica da Instituição especificamente para monitorização de pressão intrapericárdica. Removeu-se então o cateter do espaço pericárdico e se retirou todo o conjunto intracardíaco.

Diante do sangramento pericárdico presente em alguns animais, que evoluíram para tamponamento, houve a preocupação em se obter um dispositivo de segurança, quando a pressão negativa não fosse o suficiente para conter o sangramento. Após a pesquisa sobre as próteses existentes para oclusão de orifícios interatriais, optou-se pela Prótese PREMERE ${ }^{\mathrm{TM}}$ (20 mm - Sistema de Fechamento do Forame Oval Patente - St. Jude Medical), por seu baixo perfil, liberação individual de cada âncora, e com distância regulável entre elas. (Figura 7)

Em três animais, após a retirada do cateter multiperfurado e mantendose a bainha no espaço pericárdico, introduziu-se o guia e se procedeu à substituição da bainha de Mullins pela bainha de entrega PREMERE ${ }^{T M}$ (Modelo 0415-001 - Ângulo de curvatura 25 graus). Através desta avançouse o dispositivo PREMERE ${ }^{T M}$ de $20 \mathrm{~mm}$ de diâmetro que foi utilizado para oclusão do orifício da perfuração atrial. (Figura 8)

Liberada a primeira âncora no espaço pericárdico, houve o recuo do conjunto em direção à parede do átrio direito, promovendo um ajuste da 
primeira âncora à face epicárdica da parede atrial. Estando posicionada a primeira âncora ajustada à parede atrial, com a bainha de entrega recuada para o interior da cavidade atrial direita, a segunda âncora do sistema PREMERE ${ }^{T M}$ foi liberada no átrio direito, avançando-a em direção à primeira âncora, através do fio condutor, contra a face endocárdica do orifício na parede atrial. Realizado o ajuste e fixação das âncoras do sistema, ocluindose assim o orifício da perfuração atrial, procedeu-se à liberação do sistema, através do mecanismo próprio de secção do fio condutor.

Os animais permaneceram monitorizados pelos 30 minutos seguintes à liberação das próteses ou à retirada do conjunto intracardíaco, com medidas de pressão arterial invasiva, eletrocardiografia e radiologia anatômica, para avaliação de hemopericárdio e/ou tamponamento.

Foram sacrificados os 20 animais, sob anestesia geral, quando foi realizada injeção in bolus de $50 \mathrm{mEq} / \mathrm{l}$ de cloreto de potássio intravenoso (IV). Registrada assistolia, realizou-se a toracotomia e a análise macroscópica do pericárdio, seguida da retirada do coração suíno.

A análise do material histopatológico foi conduzida pelo Serviço de Anatomia Patológica da Instituição (InCor/HC-FMUSP). Foram avaliados critérios como volume (peso em gramas) de hematoma intrapericárdico; presença ou ausência de trombos no local da punção, macro e microscopicamente; presença de lesão transmural no local da punção; presença de lesão transmural no local de aplicação; modo de propagação da energia de radiofreqüência; presença de vacuolização das células no local 
de aplicação, diferenças na histopatologia entre aplicações com 4 mm e com $8 \mathrm{~mm}$, por cortes patológicos corados com hematoxilina-eosina.

Foram registradas medidas de frequência cardíaca $(F C)$ média inicial e final, pressão arterial (PA) média inicial e final, volume de hemopericárdio aspirado durante e ao término do procedimento, tempo de procedimento e tempo de radioscopia. As punções transatriais e as lesões cardíacas pela $\mathrm{RF}$ foram registradas macroscopicamente por fotografia e examinadas microscopicamente. Considerou-se instabilidade hemodinâmica uma queda na $\mathrm{PA}>20 \mathrm{mmHg}$ e necessidade de drogas vasoativas para manter $\mathrm{PA}>60$ mmHg. A média da PA e FC basal e após a remoção da bainha do espaço pericárdico foram comparadas usando-se $o$ teste $t$ de Student. Foram considerados significativos valores de $p<0.05$. 
RESULTADOS 


\section{4.}

O acesso ao espaço pericárdico foi conseguido com estabilidade hemodinâmica, comprovada pela monitorização da pressão arterial média (inicial $80.4 \pm 11.7 \mathrm{mmHg}$; final $86.8 \pm 9.7 \mathrm{mmHg}, \mathrm{p}=0.11$ ) e ausência de mudanças no movimento da borda cardíaca à fluoroscopia em 15 (88.2\%) dos 17 animais submetidos à técnica de punção transatrial. $\mathrm{O}$ cateter de ablação foi introduzido no espaço pericárdico, permitindo a simulação de mapeamento e ablação epicárdicos. Observou-se aumento significativo da frequência cardíaca média, comparando-se a inicial e a final durante o procedimento ( $F C$ inicial $101.2 \pm 12.0 \mathrm{bpm}$; final $119.7 .1 \pm 12.3 \mathrm{bpm}, \mathrm{p}<0,001$ ). Tabela 1 
Tabela 1: Características clínicas dos animais.

\begin{tabular}{|c|c|c|c|c|c|c|c|c|c|}
\hline $\begin{array}{l}\text { ANI- } \\
\text { MAL }\end{array}$ & $\begin{array}{c}\mathrm{PESO} \\
(\mathrm{KG})\end{array}$ & 离 & $\begin{array}{l}\text { RITMO } \\
\text { INICIAL }\end{array}$ & PAM & $\begin{array}{c}\text { FC } \\
\text { INICIAL }\end{array}$ & $\begin{array}{c}\text { FC } \\
\text { FINAL }\end{array}$ & $\begin{array}{c}\text { FC } \\
\text { MÉDIA }\end{array}$ & $\begin{array}{l}\text { RITMO } \\
\text { FINAL }\end{array}$ & $\begin{array}{l}\text { CORA- } \\
\text { ÇÃO } \\
(\mathrm{g})\end{array}$ \\
\hline P01 & 25 & $M$ & SINUSAL & 100 & 110 & 130 & 120 & SINUSAL & 140 \\
\hline P02 & 28 & $\bar{F}$ & SINUSAL & 84 & 110 & 110 & 110 & SINUSAL & 133 \\
\hline P03 & 30 & $F$ & SINUSAL & 90 & 115 & 125 & 120 & SINUSAL & 156 \\
\hline P04 & 25 & $\bar{F}$ & SINUSAL & 90 & 96 & 124 & 110 & SINUSAL & 130 \\
\hline P05 & 28 & $M$ & SINUSAL & 88 & 100 & 116 & 108 & SINUSAL & 142 \\
\hline P06 & 30 & $F$ & SINUSAL & 88 & 80 & 140 & 110 & SINUSAL & 220 \\
\hline P07 & 26 & $\bar{F}$ & SINUSAL & 80 & 102 & 138 & 120 & SINUSAL & 132 \\
\hline P08 & 27 & $M$ & SINUSAL & 84 & 100 & 100 & 100 & SINUSAL & 140 \\
\hline P09 & 28 & $F$ & SINUSAL & 90 & 105 & 115 & 110 & SINUSAL & 138 \\
\hline P10 & 40 & $M$ & SINUSAL & 90 & 120 & $>280$ & 120 & TV/FV & 226 \\
\hline P11 & 26 & $M$ & SINUSAL & 70 & 80 & 120 & 100 & SINUSAL & 153 \\
\hline P12 & 27 & $M$ & SINUSAL & 90 & 90 & 130 & 110 & SINUSAL & 142 \\
\hline $\mathrm{P} 13$ & 23 & $M$ & SINUSAL & 80 & 120 & 120 & 120 & SINUSAL & 148 \\
\hline P14 & 25 & $\mathrm{~F}$ & SINUSAL & 70 & 88 & 132 & 110 & SINUSAL & 206 \\
\hline P15 & 26 & $M$ & SINUSAL & 70 & 122 & 138 & 130 & SINUSAL & 192 \\
\hline P16 & 22 & $M$ & SINUSAL & 80 & 100 & 120 & 110 & SINUSAL & 180 \\
\hline P17 & 32 & $M$ & SINUSAL & 100 & 103 & 137 & 120 & SINUSAL & 240 \\
\hline P18 & 30 & $M$ & SINUSAL & 100 & 100 & 120 & 110 & SINUSAL & 225 \\
\hline P19 & 31 & $\mathrm{~F}$ & SINUSAL & 70 & 90 & 110 & 100 & SINUSAL & 143 \\
\hline P20 & 29 & $M$ & SINUSAL & 70 & 105 & 95 & 100 & SINUSAL & 153 \\
\hline Média & 27.9 & & & 84.2 & 101.8 & 122.1 & 111.9 & & 166.9 \\
\hline $\begin{array}{l}\text { Desvio- } \\
\text { padrão }\end{array}$ & 3.8 & & & 10.2 & 8.3 & 8.3 & 8.3 & & 37.0 \\
\hline
\end{tabular}

Legenda:

$\mathrm{C}=$ coração, $\mathrm{M}=$ masculino, $\mathrm{F}=$ feminino, $\mathrm{TV}=$ taquicardia ventricular, $\mathrm{FV}=$ fibrilação ventricular, P01-20= porco 01 a 20.

O Mapeamento e aplicação de radiofrequência foram realizados em diferentes posições da superfície epicárdica em átrios direito e esquerdo (duração média do procedimento $194.5 \pm 39.4$ min). Tabela 2 
Tabela 2: Características dos procedimentos.

\begin{tabular}{|c|c|c|c|c|c|}
\hline ANIMAL & $\begin{array}{c}\text { PUNÇÃO } \\
\text { TRANSATRIAL } \\
\text { POSSÍVEL } \\
\text { (Sim/Não) }\end{array}$ & $\begin{array}{l}\text { LOCAL DE } \\
\text { PUNÇÃO }\end{array}$ & COMPLICAÇÃO & $\begin{array}{c}\text { TEMPO DE } \\
\text { PROCEDI- } \\
\text { MENTO } \\
(\min )\end{array}$ & $\begin{array}{c}\text { TEMPO } \\
\text { DE RX } \\
\text { (min) }\end{array}$ \\
\hline P01 & Sim & $\mathrm{AE}$ & & 240 & 60 \\
\hline P02 & Sim & AAD & & 230 & 55 \\
\hline P03 & Sim & AAD/anel & TAMPONAMENTO & 260 & 56 \\
\hline P04 & Sim & AAD & & 230 & 53 \\
\hline P05 & Sim & $A A D$ & & 240 & 40 \\
\hline P06 & Sim & $A A D$ & & 220 & 40 \\
\hline P07 & Sim & AAD & & 180 & 32 \\
\hline P08 & Sim & AAD & & 200 & 45 \\
\hline P09 & Sim & AAD & & 180 & 40 \\
\hline P10 & Sim & VD & TAMPONAMENTO & 200 & 66 \\
\hline P11 & Sim & AAD & & 150 & 45 \\
\hline P12* & Sim & AAD & & 120 & 34 \\
\hline P13 & Sim & AAD & & 150 & 38 \\
\hline P14 & Sim & AAD & & 160 & 26 \\
\hline P15* & Sim & AAD & & 200 & 45 \\
\hline P16 & Sim & AAD & & 180 & 25 \\
\hline $\mathrm{P} 17^{*}$ & Sim & VD & & 220 & 40 \\
\hline P18 & Sim & AAD & & 200 & 38 \\
\hline P19 & Sim & $A A D$ & & 210 & 40 \\
\hline P20 & Sim & AAD & & 120 & 26 \\
\hline Média & & & & 194.5 & 42.2 \\
\hline $\begin{array}{l}\text { Desvio- } \\
\text { padrão }\end{array}$ & & & & 39.40011 & 11.30719 \\
\hline
\end{tabular}

${ }^{*}$ Realizado implante da prótese PREMERE ${ }^{\mathrm{TM}}$.

Legenda:

P01-20 = porco 01 a $20, A E=$ Átrio esquerdo, $A A D=$ Apêndice auricular direito, $\mathrm{VD}=$ ventrículo direito, $\mathrm{RX}=$ radioscopia 
A análise post mortem encontrou a perfuração atrial de acesso ao espaço pericárdico no $A A D$ em 13 animais, na parede lateral do átrio direito em um e no apêndice atrial esquerdo em outro.

Encontrou-se uma média de 15.2 $\pm 4.1 \mathrm{~g}$ de hematoma em 6 animais com ausência de sangramento significante nos outros 9 animais. A análise histológica demonstrou contato completo entre as bordas do orifício, provavelmente secundário à contração das fibras miocárdicas ao redor do orifício de perfuração e à presença de trombo de fibrina ocluindo na face endocárdica do átrio (Figure 9). Os cortes histológicos evidenciaram presença de trombo em 17/20 animais e com visualização do pertuito em 11/20 animais à microscopia. (Anexos $A, B$ e C)

A aspiração pericárdica de líquido sero-hemorrágico revelou uma média de volume de $31.0 \pm 26.5 \mathrm{ml} /$ animal durante o procedimento. Tabela 3 
Tabela 3: Características do sangramento e drenagem pericárdica.

\begin{tabular}{|c|c|c|c|c|c|}
\hline ANIMAL & $\begin{array}{l}\text { Sangramento } \\
\text { presente } \\
\text { (sim/não) }\end{array}$ & $\begin{array}{l}\text { Drenagem } \\
\text { imediata } \\
(\mathrm{ml})\end{array}$ & $\begin{array}{l}\text { Drenagem } \\
\text { após } 30 \mathrm{~min} \\
\quad(\mathrm{ml})\end{array}$ & $\begin{array}{c}\text { Hemopericárdio } \\
\text { na patologia } \\
(\mathrm{g})\end{array}$ & $\begin{array}{c}\text { Tampona- } \\
\text { mento } \\
\text { (Sim/Não) }\end{array}$ \\
\hline P01 & Sim & 3 & 20 & 20 & Não \\
\hline P02 & Sim & 5 & 35 & 6 & Não \\
\hline P03 & Sim & 0 & 20 & 155 & Sim \\
\hline P04 & Sim & 3 & 13 & 11 & Não \\
\hline P05 & Sim & 0 & 15 & 0 & Não \\
\hline P06 & Sim & 6 & 22 & 12 & Não \\
\hline P07 & Sim & 0 & 18 & 5 & Não \\
\hline P08 & Sim & 0 & 55 & 0 & Não \\
\hline P09 & Sim & 4 & 25 & 0 & Não \\
\hline P10 & Sim & 10 & 63 & 201 & Sim \\
\hline P11 & Sim & 5 & 30 & 12 & Não \\
\hline $\mathrm{P} 12^{*}$ & Sim & 7 & 25 & 10 & Não \\
\hline P13 & Sim & 0 & 18 & 6 & Não \\
\hline P14 & Sim & 0 & 20 & 16 & Não \\
\hline P15* & Sim & 6 & 31 & 0 & Não \\
\hline P16 & Sim & 5 & 10 & 5 & Não \\
\hline $\mathrm{P} 17^{*}$ & Sim & 22 & 42 & 0 & Não \\
\hline P18 & Sim & 5 & 20 & 5 & Não \\
\hline P19 & Sim & 0 & $12^{* *}$ & $20^{* *}$ & Não \\
\hline P20 & Sim & 0 & 120 & 2 & Não \\
\hline Media & & 4.05 & 31.68 & 24.52 & \\
\hline $\begin{array}{l}\text { Desvio- } \\
\text { padrão }\end{array}$ & & 5.18 & 25.43 & 54.93 & \\
\hline
\end{tabular}

${ }^{*}$ Realizado implante da prótese PREMERE ${ }^{\mathrm{TM}}$. ${ }^{* *}$ Observado obstrução do pigtail pósretirada.

Legenda:

P01-20 = porco 01 a $20, A E=$ Átrio esquerdo, $A A D=$ Apêndice auricular direito, $\mathrm{VD}=$ ventrículo direito. 
Sangramento pericárdico importante e tamponamento cardíaco ocorreram em dois animais dos dez iniciais durante mapeamento epicárdico e ablação. O animal de número 3 foi o primeiro, revelando post mortem $155 \mathrm{~g}$ de hematoma no espaço pericárdico e a perfuração atrial foi identificada no AAD, na face anterior do anel tricúspide. (Figura 10)

O segundo tamponamento ocorreu no animal de número 10, cuja análise post mortem revelou $201 \mathrm{~g}$ de hematoma no espaço pericárdico e a perfuração foi identificada na via de saída do ventrículo direito.

Um achado interessante foi que o peso dos animais que apresentaram tamponamento foi maior que dos sem tamponamento $(26.9 \pm 2.6$ vs. $35.0 \pm$ $7.1 \mathrm{~kg} ; \mathrm{p}=0,003)$, pesando $30 \mathrm{~kg}$ e $40 \mathrm{~kg}$, respectivamente os animais de número 3 e 10.

Os três procedimentos para implante do dispositivo com o objetivo de oclusão dos orifícios de perfuração cardíaca, dois no AAD e um na via de saída de ventrículo direito, ocorreram sem intercorrências. Os animais mantiveram estabilidade hemodinâmica durante todo o procedimento e a análise post mortem revelou que, apesar destes dispositivos não terem sido desenhados para esse propósito, houve um bom funcionamento, (Figura 11), com ausência de sangramento pericárdico significativo. Tabela 4 
Tabela 4: Características do sangramento e drenagem pericárdica com o uso do dispositivo oclusor.

\begin{tabular}{|c|c|c|c|c|c|c|c|}
\hline 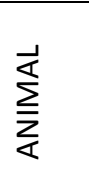 & $\begin{array}{c}\text { PESO } \\
(\mathrm{Kg})\end{array}$ & 导 & $\begin{array}{l}\text { Sangramento } \\
\text { presente } \\
\text { (sim/nao) }\end{array}$ & $\begin{array}{c}\text { Drena- } \\
\text { gem } \\
\text { imediata } \\
(\mathrm{ml})\end{array}$ & $\begin{array}{c}\text { Drenagem } \\
\text { apos } 15 \\
\min (\mathrm{ml})\end{array}$ & 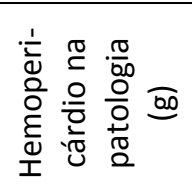 & 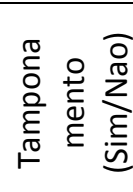 \\
\hline P12* & 27 & 110 & Sim & 7 & 25 & 10 & Não \\
\hline P15* & 26 & 130 & Sim & 6 & 31 & 0 & Não \\
\hline P17* & 32 & 120 & Sim & 22 & 42 & 0 & Não \\
\hline
\end{tabular}

As aplicações de radiofrequência demonstradas por lesões histopatológicas na face epicádica do tecido atrial confirmaram a presença dos cateteres no espaço pericárdico. (Figura 12) 
DISCUSSÃO 


\section{Discussão}

A principal observação deste estudo foi a demonstração da viabilidade da técnica do acesso ao espaço pericárdico através da punção transatrial no apêndice atrial direito, permitindo a introdução de cateteres de eletrofisiologia, com a finalidade de realização de mapeamento e ablação epicárdica das arritmias cardíacas.

Um discreto derrame pericárdico ocorreu na maioria dos casos, entretanto sem instabilidade hemodinâmica significativa. Provavelmente, a contração das fibras miocárdicas atriais ao redor do orifício transatrial evita um sangramento significativo durante o procedimento. Após a retirada total do sistema transatrial, o mecanismo de prevenção de sangramento pericárdico continuado se baseia na contração miocárdica persistente associada à formação de trombo no orifício. $\mathrm{O}$ acesso transvenoso pode ser uma alternativa para realização de mapeamento e ablação epicárdica da superfície dos átrios e ventrículos, para os eletrofisiologistas que não se sentem confortáveis com o acesso subxifóide.

\section{Punção transatrial}

O conceito de punção transatrial foi inicialmente introduzido em 1998 por Verrier et $\mathrm{al}^{73}$ para acesso ao espaço pericárdico. Neste estudo experimental com 19 animais (6 cães e 13 suínos), foi acoplada uma agulha côncava radiopaca à ponta de um cateter $4 \mathrm{~F}$ e juntamente com uma guia 0.014, foram utilizadas para realizar acesso percutâneo ao $A A D$ via veia 
femoral . Não apresentaram hemopericárdio à toracotomia, nem laceração ou sangramento na retirada do cateter. Esses achados foram confirmados em seu trabalho subsequente, envolvendo 20 porcos, onde o acesso transatrial foi conseguido dentro de 3 minutos, sem derrame pericárdico significativo após 24 horas e 2 semanas de evolução.

No presente estudo, apesar da não utilização de material específico, os achados foram similares aos daqueles autores, quando o acesso pericárdico foi obtido através do apêndice atrial. A presença de maior sangramento e derrame pericárdico ao final deste estudo, quando comparado aos outros trabalhos, pode dever-se à presença neste de mapeamento e ablação epicárdica. Milckelsen et $\mathrm{al}^{78}$ também observaram alguns derrames pericárdicos que foram hemodinamicamente significantes, em quatro de oito animais submetidos a implante de eletrodos epicárdicos, através de acesso transatrial ou transvenoso (veia cava superior). Eles também utilizaram material não específico e de maior diâmetro (bainhas 8F e 9F) para acessar o espaço pericárdico, o que deve ter facilitado o sangramento. Mas não houve derrame pericárdico significativo à necrópsia, encontrando-se uma reação inflamatória moderada em dois animais cronicamente, que apresentaram hemopericárdio importante durante o procedimento. Esses achados preocupam porque se sabe que pericardite intensa e até mesmo constritiva tem sido observada após ocorrência de hemopericárdio. ${ }^{90}$ Entretando, existem trabalhos experimentais demonstrando que infusão intrapericárdica de esteróides promove redução importante da pericardite 
inflamatória após mapeamento e ablação epicárdica, podendo ser útil na prevenção desta complicação. ${ }^{91}$

\section{Punção epicárdica}

A punção epicárdica subxifóide para tratamento de tamponamento cardíaco vem sendo realizada há muitos anos desde sua primeira descrição por Krikorian et al. ${ }^{58}$ em 1978 com sucesso, e posteriormente utilizada por Sosa et al. $^{65}$ para acesso ao espaço pericárdico na ausência de sangramento para mapeamento e ablação epicárdica. Ao longo dos últimos 14 anos desde sua descrição com esta finalidade, o índice de complicações, principalmente sangramento tem situado em torno de 10 a $20 \%$, dependendo da experiência do serviço.

Outra preocupação importante, é que continua sendo uma técnica desconfortável para o paciente e para o eletrofisiologista, e a busca de uma abordagem transvascular para acesso ao espaço vem sendo discutida e pesquisada no Serviço de Arritmias do InCor. Nesse trabalho foi possível acessar o espaço pericárdico em todos os animais estudados, inclusive nos dois animais que por erro de técnica, procedeu-se a punção através da parede ventricular e do anel tricúspide. Atingiu-se com o cateter deflectível através da bainha de Mullins situada no espaço pericárdico todas a câmaras cardíacas, nas mais diversas posições, permitindo liberação de energia de radiofrequência nos átrios para posterior análise histopatológica. 0 pericárdio permaneceu íntegro em todos os espécimes. 


\section{Oclusão do orifício}

O hemopericárdio normalmente ocorre após uma perfuração cardíaca acidental devido a pressão dentro da câmara cardíaca ser maior que a intrapericárdica, assim como pela falência dos mecanismos hemostáticos vasculares regulares presentes na parede miocárdica em prevenir sangramento persistente. O mecanismo pelo qual o acesso transatrial não promoveu sangramento pericárdico é intrigante, principalmente após a retirada dos cateteres. A questão porque o sangue não flui pelo orifício atrial criado após a remoção dos cateteres é fascinante. A explicação mais provável seria que o átrio direito é uma câmara de baixa pressão e que a contração do músculo atrial ao redor do orifício reduziria o diâmetro da perfuração durante a manipulação e retirada dos cateteres. Isto oferece tempo e oportunidade para a formação de trombo ao redor da superfície endocárdica do orifício, trombo este, que ocluiria o orifício quando finalmente o cateter fosse retirado. Neste estudo, exames macroscópicos imediatos e histológicos mostraram uma redução espontânea importante do orifício de perfuração atrial, após a retirada dos cateteres devido à contração das fibras miocárdicas ao redor do orifício. Avaliação microscópica revelou formação de fibrina na superfície endocárdica das punções, que provavelmente também contribuíram para a ausência de derrame pericárdico. Esses achados estão em conformidade com os trabalhos de Verrier ${ }^{73}$ e Waxman $^{75}$, que relataram a observação de trombos de fibrina no lado endocárdico.

Interessante ressaltar que o animal que teve seu acesso transatrial através do átrio esquerdo apresentou o mesmo comportamento dos outros 
em $A A D$, e não apresentou sangramento. Parece que a anatomia do $A A D$ e esquerdo em porcos favorece a formação local de trombos. O papel da pressão negativa intrapericárdica para evitar o sangramento pericárdico ainda não está claro. Esta manobra tem sido utilizada juntamente com a redução progressiva do calibre dos cateteres em perfurações acidentais de átrio durante acesso transeptal ao átrio esquerdo, assim como foi realizada no presente estudo. A hipótese é que seu uso promoveria uma pressão intrapericárdica negativa enquanto a perfuração ainda está ocluída, promovendo uma adesão local entre as membranas visceral e parietal do pericárdio, selando o lado epicárdico da perfuração. Esta condição poderia favorecer a formação de trombos no orifício.

Com a taxa de sangramento inicial nos primeiros 10 animais de $20 \%$ de tamponamento motivou a busca por próteses que pudessem ocluir o orifício, que reduziu para $11,7 \%$ com o aumento da amostra. A prótese PREMERE ${ }^{T M}$ foi escolhida por seu perfil pequeno, com a liberação das duas âncoras separadamente, com ajuste flexível da distância entre as duas âncoras, podendo se adaptar às diferentes espessuras da parede do átrio. $\mathrm{O}$ implante da primeira prótese PREMERE ${ }^{T M}$ ocorreu sem dificuldades técnicas posicionada na parede anterior do átrio direito, que permitiu a abertura completa das duas âncoras sem intercorrências. A segunda prótese liberada propositadamente na ponta do apêndice auricular direito apresentou abertura completa da âncora no espaço intrapericárdico, e parcial no interior do átrio direito promovendo também uma oclusão do AAD. A última PREMERE $^{\mathrm{TM}}$ foi posicionada para oclusão de perfuração em trato de saída 
do ventrículo direito, apresentando aberturas completas das âncoras e eficácia na prevenção de tamponamento em perfuração ventricular acidental. A hipótese inicial de um oclusor do orifício transatrial é totalmente inovadora, tendo sido este tipo de prótese transvascular utilizada até o presente momento apenas para oclusão de orifícios intracardíacos.

Acredita-se que poderia haver o desenvolvimento de próteses ou materiais absorvíveis que pudessem ser utilizados para oclusão aguda do orifício. Sua extensão seria possível para oclusão de acidentes de punção seguidos de perfuração da parede atrial, descritos na literatura como complicação durante punção transeptal ou manipulação de cateteres no átrio esquerdo durante ablação de fibrilação atrial, evitando-se assim, a necessidade de toracotomia para atriorrafia.

\section{Limitações}

Por ser um estudo experimental realizado em animais suínos, não se pode assumir que, caso realizado em humanos, observaremos o mesmo comportamento. Além disso, foi um estudo de fase aguda e os procedimentos foram realizados sem heparinização dos animais. $\mathrm{Na}$ presença de anticoagulação sistêmica, possivelmente, as condições locais dos orifícios seriam diferentes e o sangramento pericárdico poderia ser mais importante. Apesar de a anticoagulação não ser necessária quando o mapeamento e a ablação são realizados na superfície epicárdica do coração por acesso subxifóide, fazem-se necessários estudos adicionais para avaliar o efeito da anticoagulação na segurança da punção transatrial, 
principalmente quando o foco do procedimento for o mapeamento e a ablação combinada no endocárdio e no epicárdio. Kassab et al ${ }^{79}$ utilizaram 10.000 IU IV de heparina em seu estudo para avaliar a eficácia da inserção de eletrodos epicárdicos através de acesso transatrial, utilizando material específico, e não observaram derrame pericárdico em 10 suínos (5 agudos e 5 crônicos).

Importante ressaltar que dois animais apresentaram tamponamento cardíaco e colapso hemodinâmico durante a punção transatrial para acesso ao espaço pericárdico. Em ambos os casos, as bainhas pareciam curtas para permanecerem estáveis dentro do AAD e as punções foram realizadas acidentalmente no anel tricúspide e na parede do VD. Portanto, uma segunda confirmação, infundindo contraste através do dilatador antes de transfixar o AAD, deve ser realizada para verificar se as bainhas permanecem em posição correta.

As bainhas e cateteres utilizados foram de largo calibre. Provavelmente, a segurança do procedimento seria maior com o uso de materiais mais delicados. Assim, materiais específicos para esse propósito podem aumentar a segurança do procedimento.

Outro ponto essencial é que o acesso transatrial para o espaço pericárdico é uma perfuração programada que cria um risco em potencial para sangramento pericárdico e tamponamento cardíaco. De um ponto de vista otimista, sabe-se onde o orifício está sendo criado e, portanto, mais fácil sua localização para que se proceda à oclusão através de técnica específica. Neste estudo esta hipótese foi parcialmente avaliada com o 
implante de próteses adaptadas para essa função, no entanto, equipamentos mais apropriados e estudos de validação são necessários antes que se assumam os riscos.

O tamanho reduzido e a diferente angulação do apêndice atrial direito no coração suíno em relação ao humano, onde os operadores possuem sua maior experiência, poderiam estar associados ao maior número de hemopericárdio e tamponamento na experiência inicial da técnica. A presença de um segundo método de imagem associado, como ecocardiograma intracardíaco ou transesofágico, durante o avanço da bainha no momento da punção transatrial e o posicionamento das próteses, poderia se associar a aumento da segurança da técnica. 
CONCLUSÕES 


\section{Conclusões}

O acesso transatrial percutâneo através do apêndice atrial direito é viável e permite a exploração do espaço pericárdico. Este acesso pode ser uma alternativa potencialmente útil para mapeamento e ablação epicárdica das arritmias cardíacas, assim como para drenagem rápida de tamponamento cardíaco agudo. Devido ao risco potencial de hemopericárdio, são necessários mais estudos para avaliar sua segurança antes de sua aplicação clínica.

A utilização de sistema de oclusão de orifícios interatriais para fechamento de pertuito transmural, gerado pela punção para acesso pericárdico, parece adicionar segurança na retirada das bainhas do espaço pericárdico, porém são necessários mais estudos para sua avaliação específica. 
ANEXOS 


\section{Anexos}

ANEXO A: Figura 1 - Imagem radiológica. Oblíqua anterior direita a 30‥ (a) Cateter multipolar posicionado no interior do seio coronário e quadripolar deflectível com ponta $8 \mathrm{~mm}$ em His. (b)Registro eletrocardiográfico e eletrogramas endocavitários em seio coronário (SC) e His (RAA), proximal (p) a distal (d).

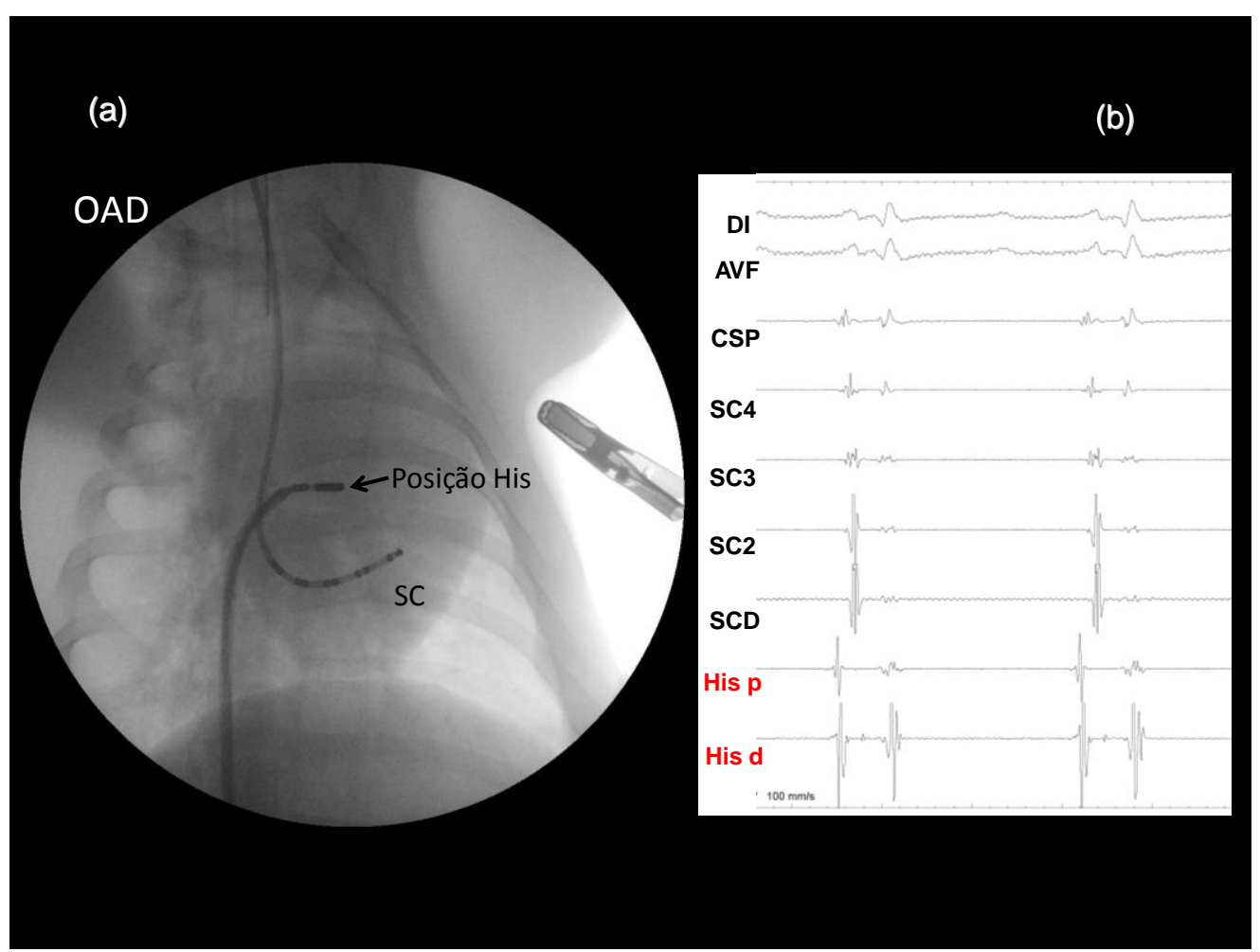


ANEXO B: Figura 2 - Imagem radiológica. Oblíqua anterior direita a $30^{\circ}$. (a) Cateter multipolar posicionado no interior do seio coronário e quadripolar deflectível com ponta $8 \mathrm{~mm}$ em átrio direito. (b) Registro eletrocardiográfico e eletrogramas endocavitários em seio coronário (SC) e apêndice atrial direito (RAA), proximal (p) a distal (d).

(a)

(b)

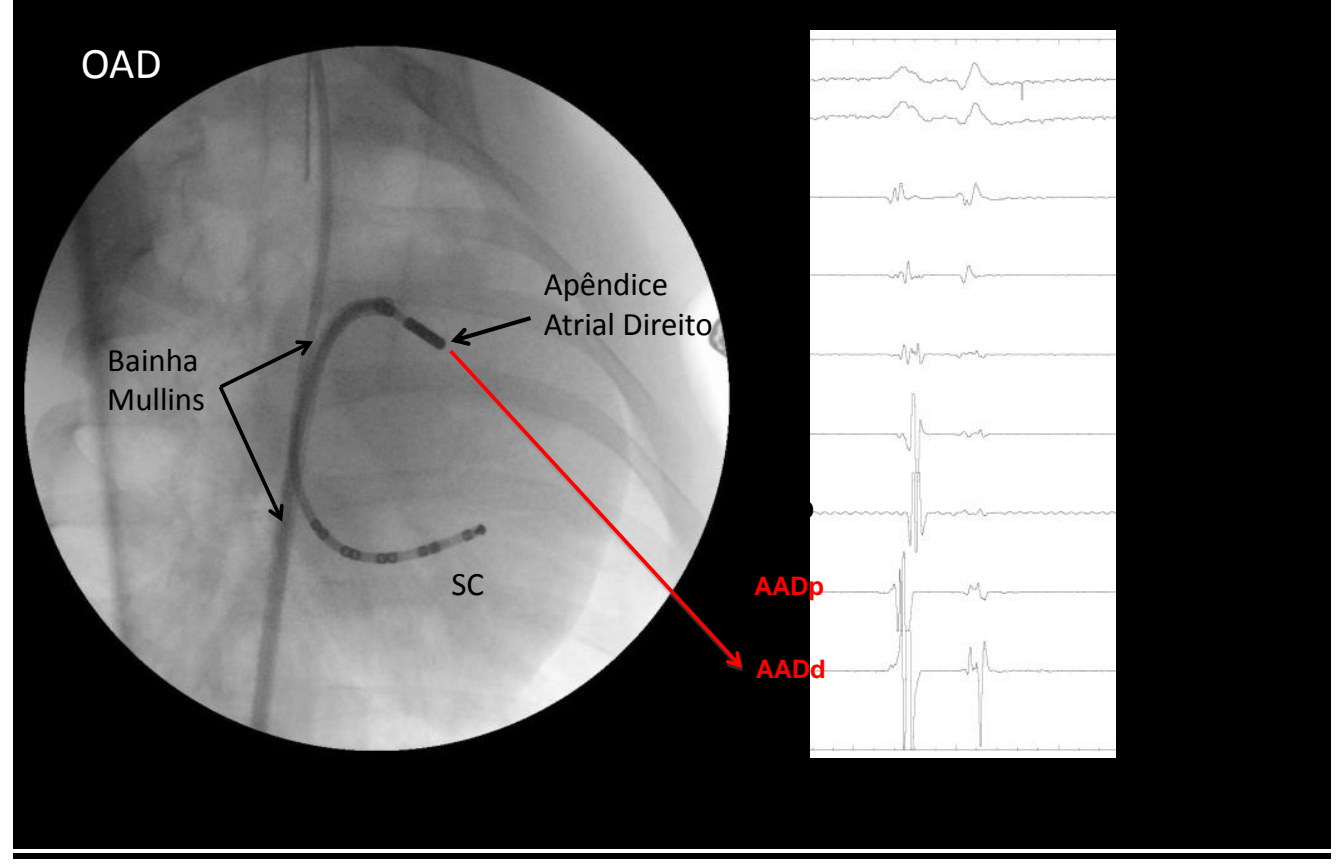


ANEXO C: Figura 3 - Imagem radiológica. Oblíqua anterior direita a $30^{\circ}$. Cateter multipolar posicionado no interior do seio coronário. Contraste evidenciando anatomia do átrio direito.

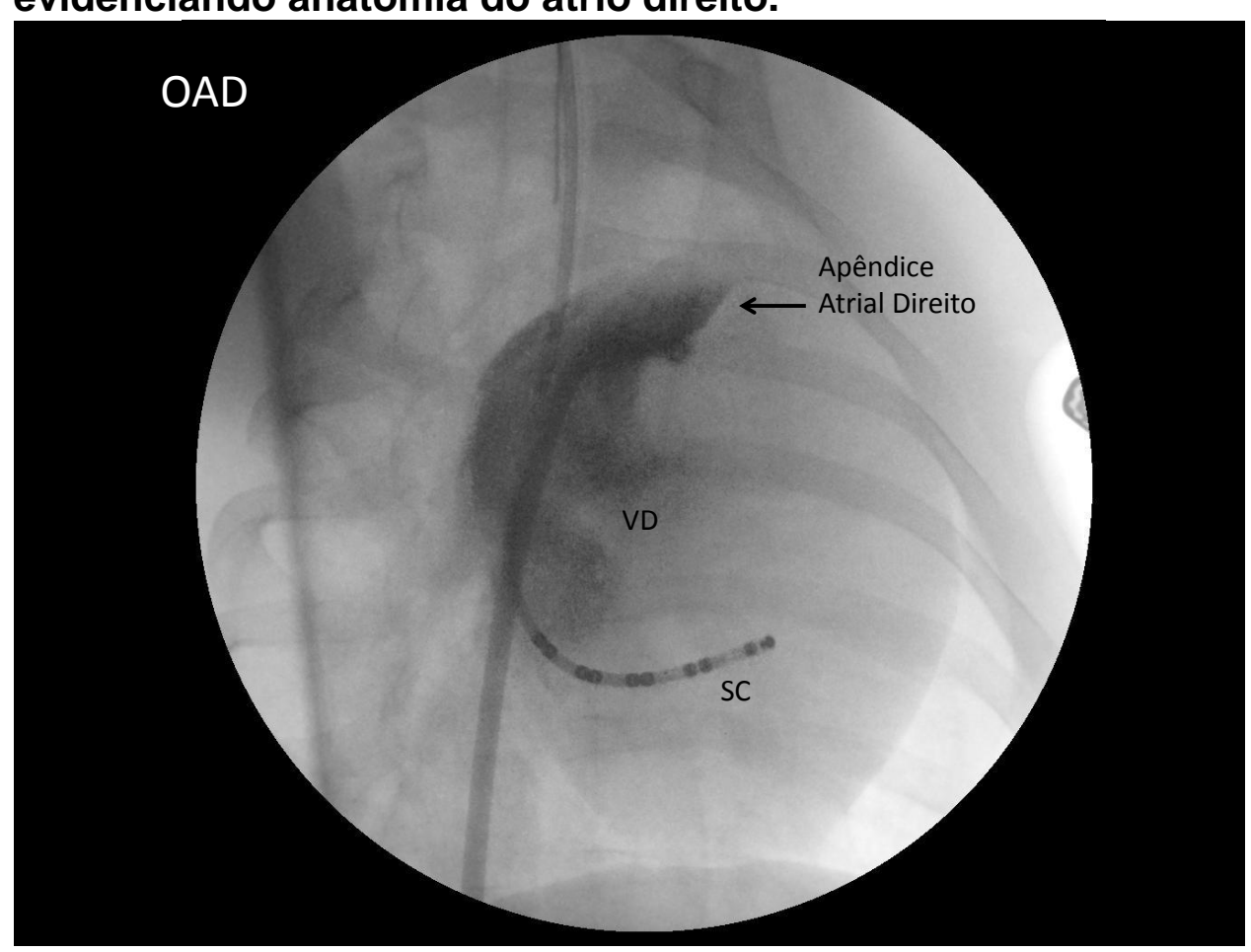


ANEXO D: Figura 4 - Sequência radiológica em póstero-anterior (PA). Avanço do guia e dilatador para o espaço pericárdico. Avanço contra a parede do apêndice atrial direito (a). Avanço de dilatador e guia no espaço pericárdico (b).

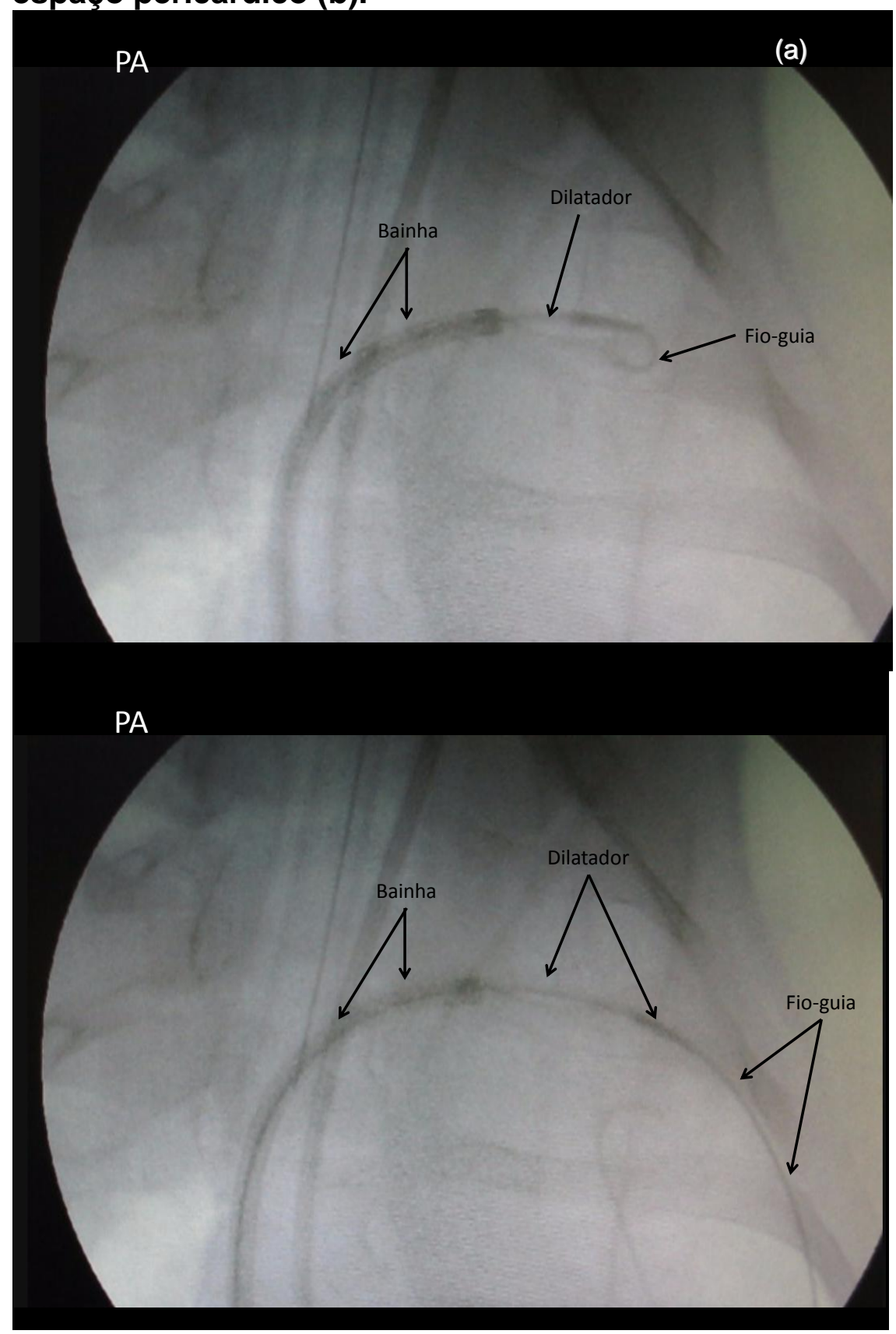


ANEXO E: Figura 5 - Imagem radiológica em póstero-anterior (PA). Avanço da bainha de Mullins para o espaço pericárdico, dilatador e guia no epicárdio.

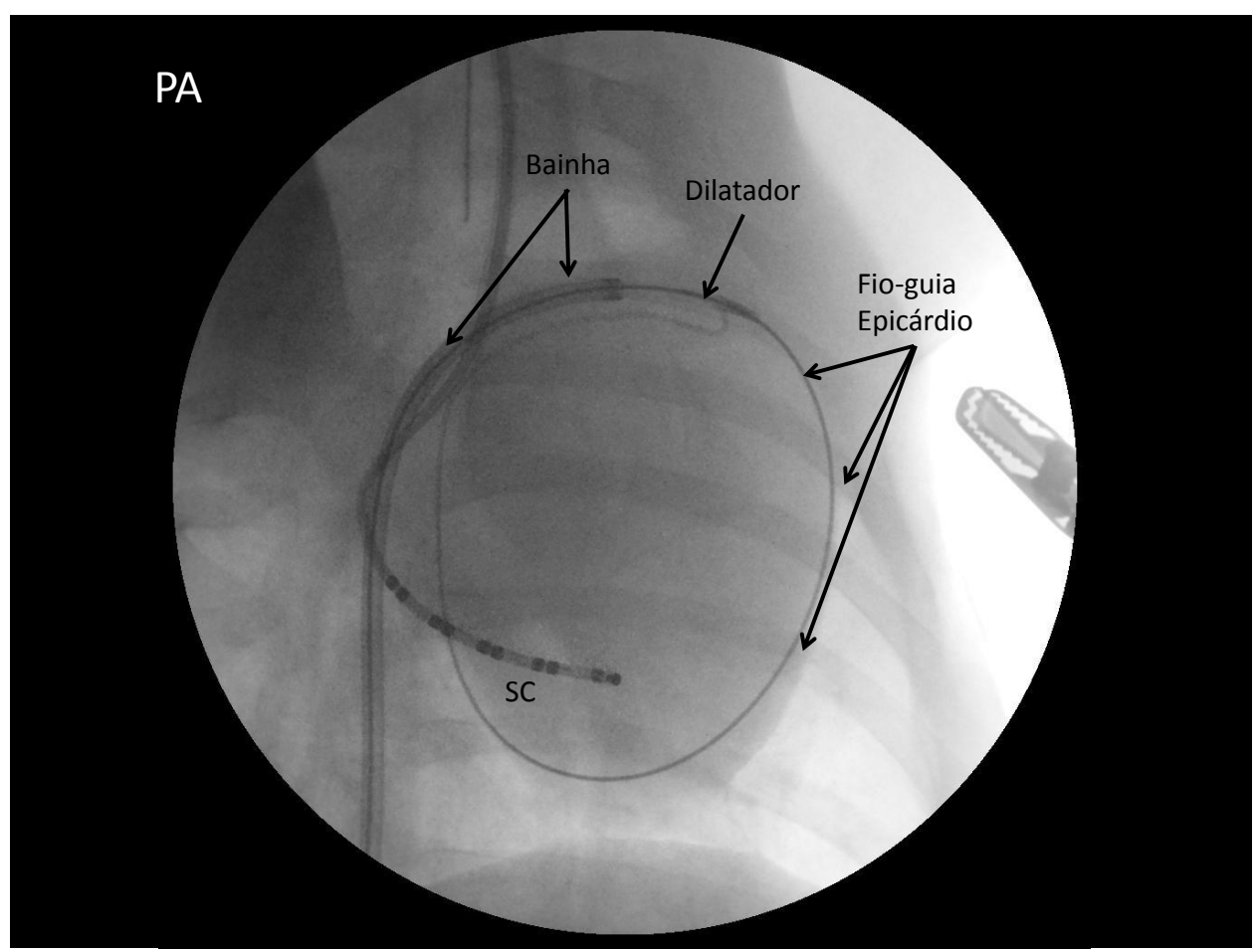


ANEXO F: Figura 6 - Sequência radiológica. Em póstero-anterior (PA), cateter multipolar posicionado no interior do seio coronário (SC), bainha de Mullins e cateter quadripolar $8 \mathrm{~mm}$ no espaço pericárdico de átrio direito (a). Em oblíqua anterior direita 30o, cateter multipolar posicionado no interior do seio coronário, bainha de Mullins e cateter quadripolar $8 \mathrm{~mm}$ no espaço pericárdico de átrio esquerdo (b).
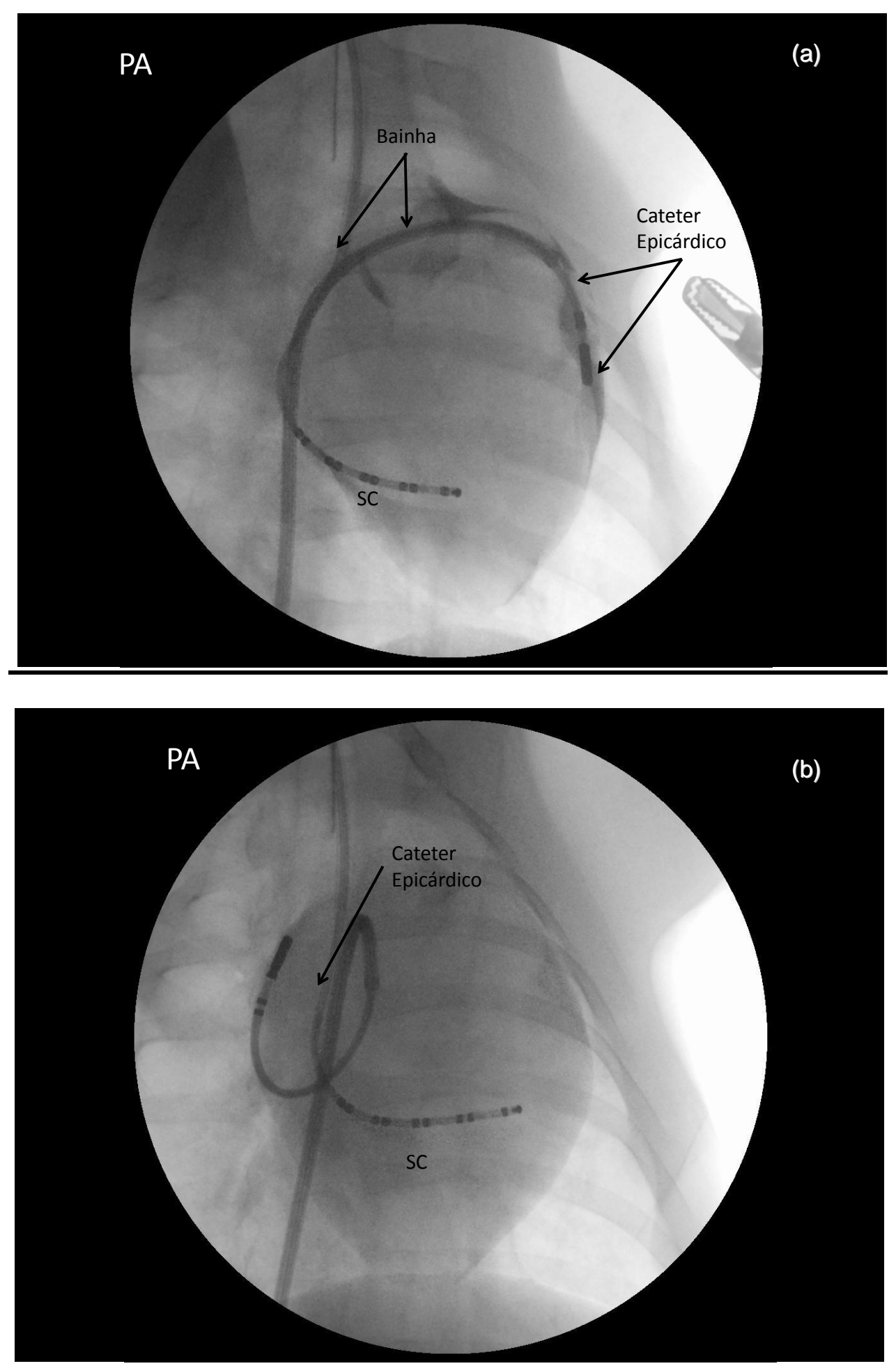
ANEXO G: Figura 7 - Foto da prótese PREMERE ${ }^{\mathrm{TM}}$ com suas duas âncoras (a). Desenho esquemático da prótese e da bainha $\mathrm{e}$ dispositivos de entrega da prótese (b).
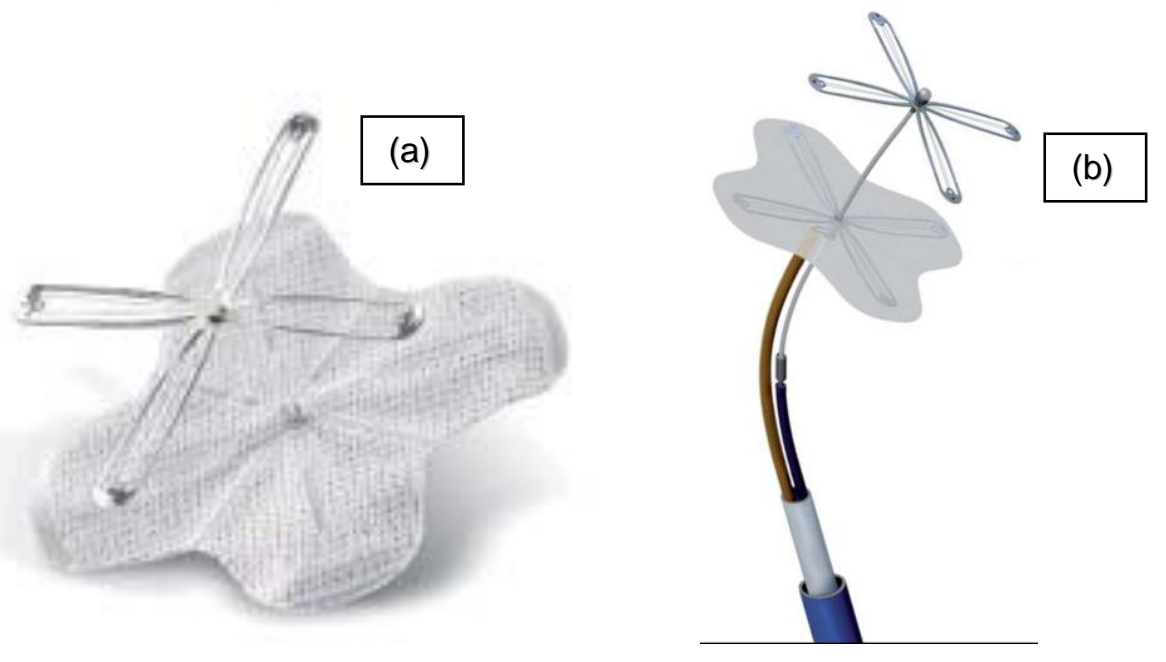
ANEXO H: Figura 8 - Sequência radiológica em oblíqua anterior direita 30 . Bainha no interior da veia cava inferior, primeira âncora no espaço pericárdico, segunda âncora do sistema PREMERE ${ }^{\mathrm{TM}}$ no interior do átrio direito(a), ambas fixadas (b), seguido da liberação do sistema (c).

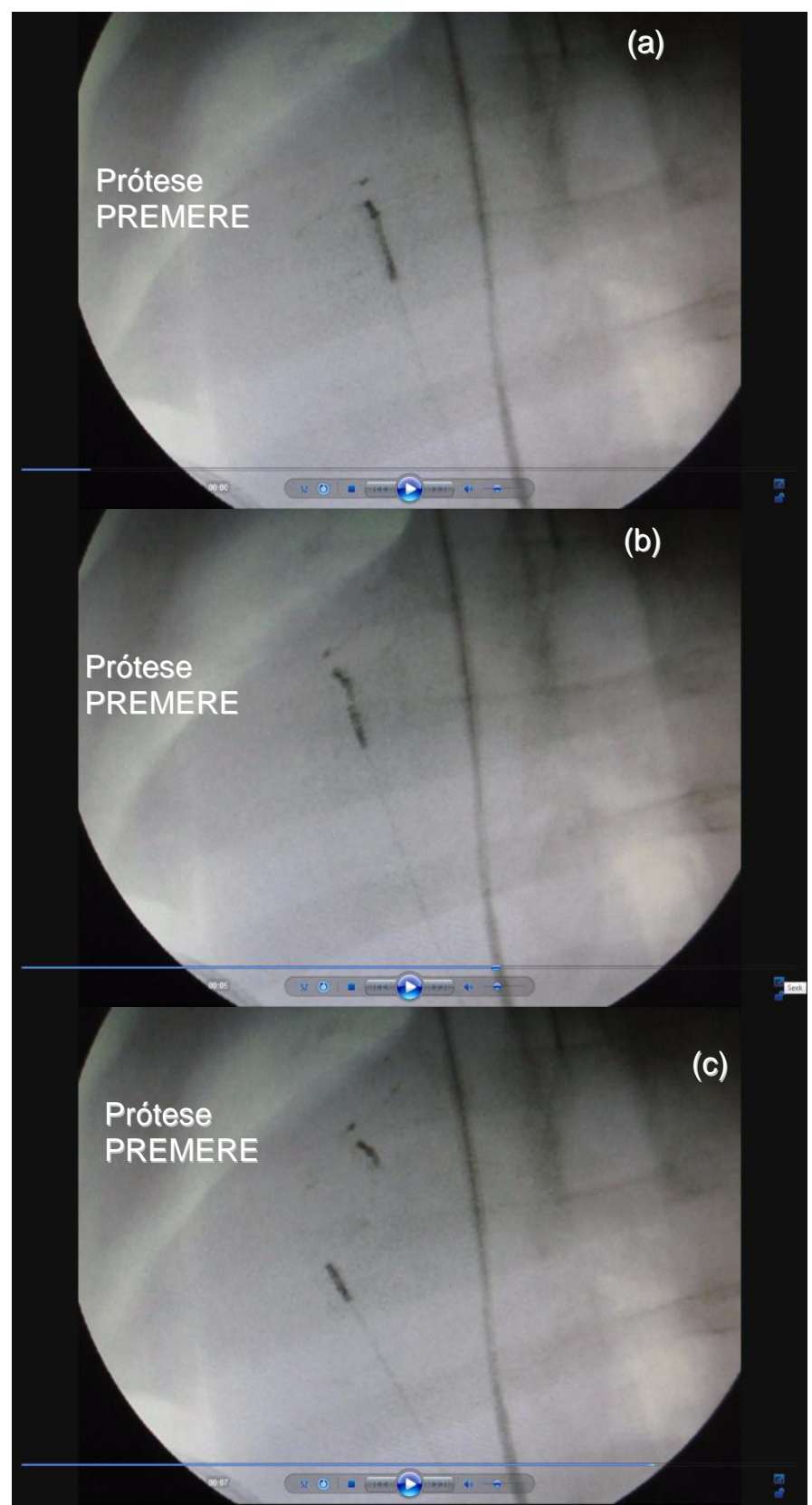


ANEXO I: Figura 9 - Fotografia da macroscopia do orifício atrial da punção transatrial (a) e da microscopia da perfuração atrial com cinco vezes de aumento (b).

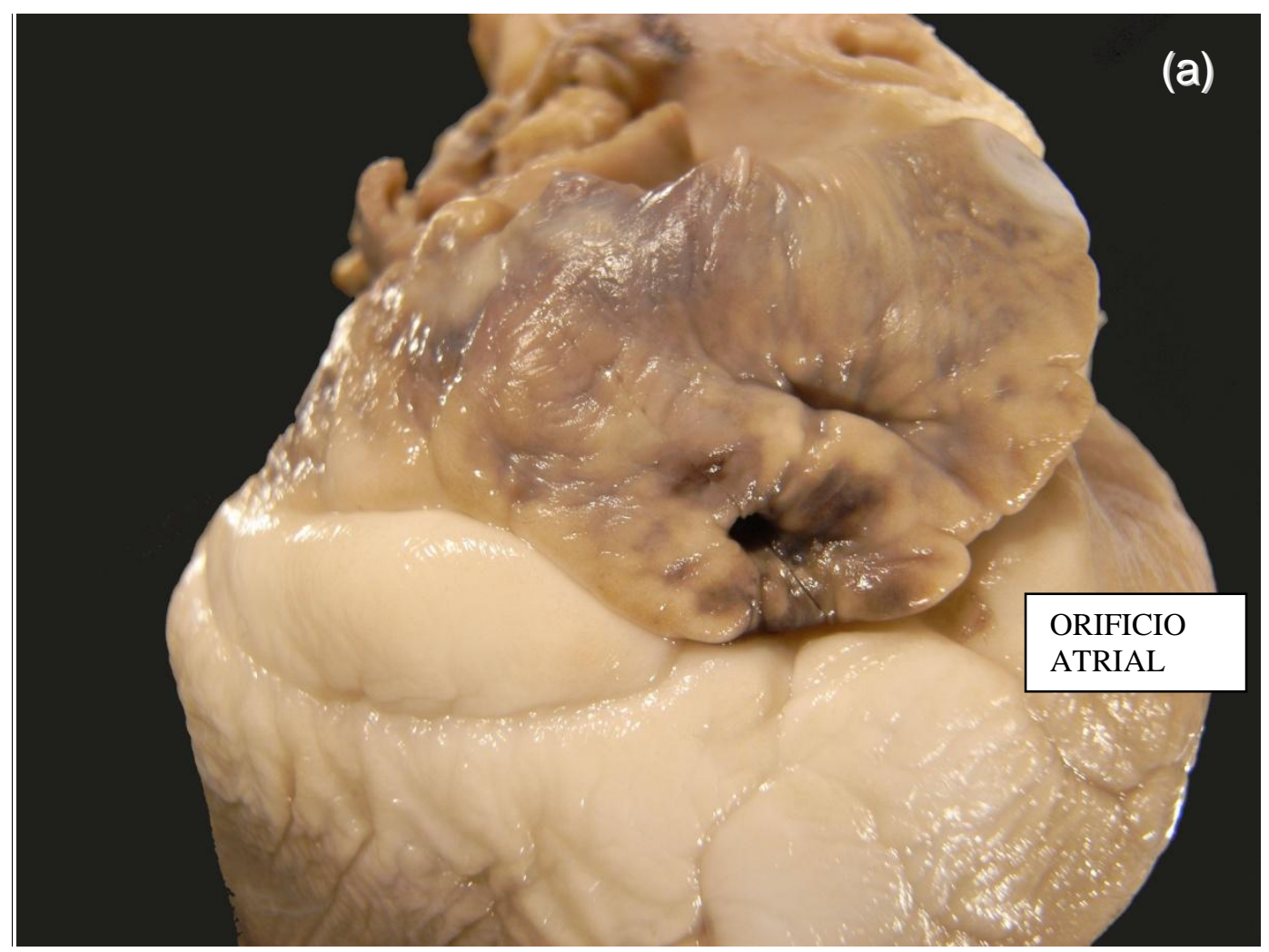

(b)

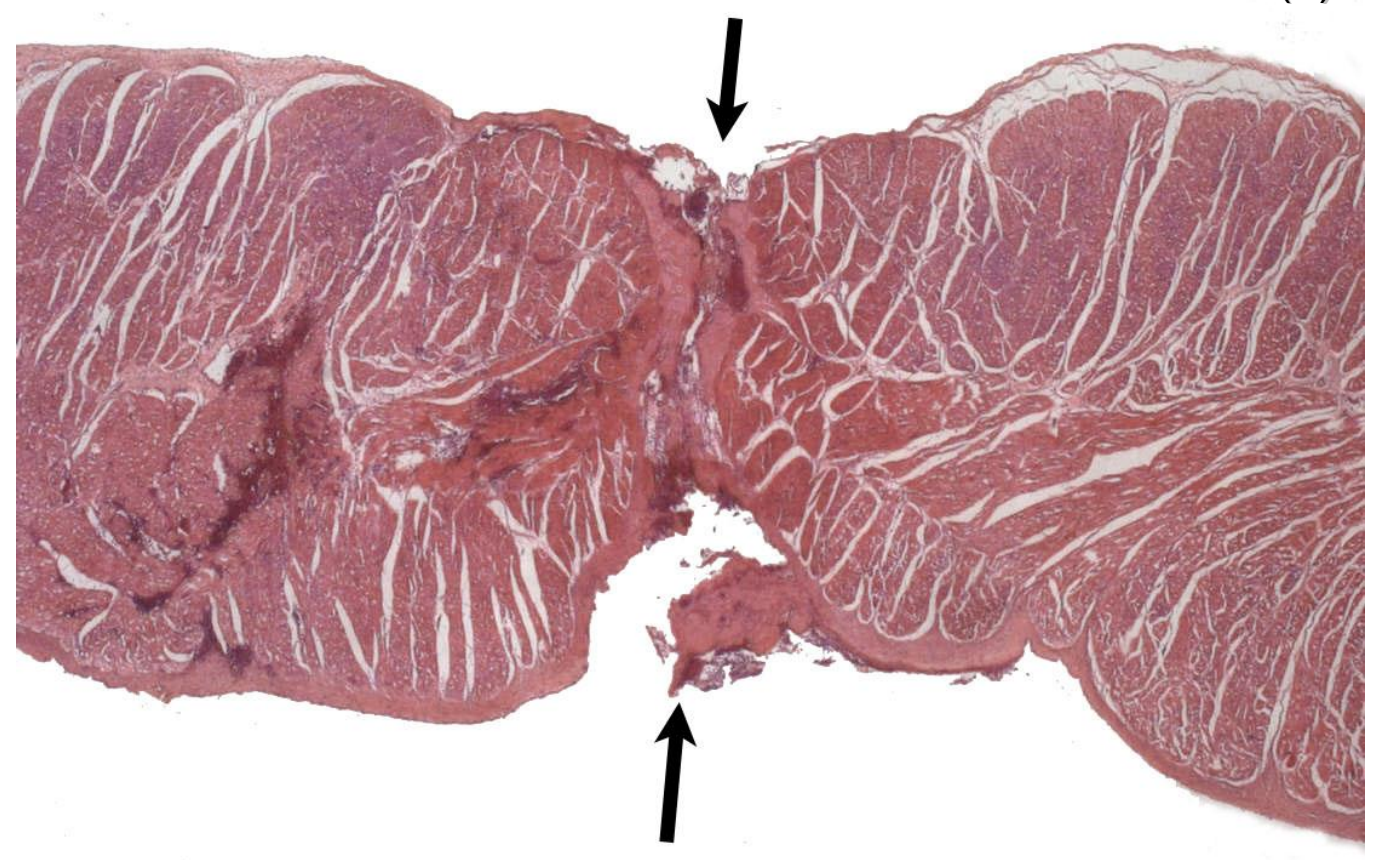




\section{ANEXO J: Características das aplicações de radiofrequência e dos achados histopatológicos (P01-P07):}

\begin{tabular}{|c|c|c|c|c|}
\hline ANIMAL & $\begin{array}{l}\text { Cateter } \\
\text { de RF }\end{array}$ & $\begin{array}{l}\text { Potência } \\
\text { (W) * }\end{array}$ & $\begin{array}{l}\text { Locais amostrados para } \\
\text { histologia }\end{array}$ & Histologia \\
\hline P01 & $N$ & -- & $\begin{array}{l}\text { Local da punção em átrio } \\
\text { esquerdo }(\mathrm{AE})\end{array}$ & AE:perfuração com trombo. \\
\hline P02 & $4 \mathrm{~mm}$ & 30 & $\begin{array}{l}\text { Local da punção em } \\
\text { apêndice atrial (AAD) + } \\
\text { Lesão na ponta do } \\
\text { apêndice atrial esquerdo } \\
\text { (AAE) }\end{array}$ & $\begin{array}{l}\text { AAD- Perfuração com trombo } \\
\text { recente ocluindo o local } \\
\text { AAE- sem lesão de RF. }\end{array}$ \\
\hline P03 & $\mathrm{N}$ & -- & $\begin{array}{l}\text { Anel átrio-ventricular (AV) } \\
\text { perfurado }\end{array}$ & $\begin{array}{l}\text { Corte mostra periferia da } \\
\text { perfuração no anel } \mathrm{AV}, \\
\text { próximo a um ramo } \\
\text { coronariano. }\end{array}$ \\
\hline P04 & $\mathrm{N}$ & -- & Local da punção em AAD + & $\begin{array}{l}\text { AAD: perfuração e trombo, } \\
\text { afundado mostrou periferia da } \\
\text { perfuração com fibrina no } \\
\text { epicárdio. }\end{array}$ \\
\hline P05 & $\mathrm{N}$ & -- & $\begin{array}{c}\text { Local da punção em AAD + } \\
\text { Face anterior ventricular } \\
\text { hemorrágica }\end{array}$ & $\begin{array}{l}\text { AAD: perfuração e trombo } \\
\text { Hemorragia intersticial do } \\
\text { miocárdio, sem necrose; }\end{array}$ \\
\hline P06 & $4 \mathrm{~mm}$ & 25 & $\begin{array}{c}\text { Local da punção em AAD+ } \\
\text { RF em tronco pulmonar } \\
\text { (TP) }\end{array}$ & $\begin{array}{c}\text { AAD: periferia da perfuração } \\
\text { com fibrina no epicárdio: RF- } \\
\text { TP: lesão com vacuolização } \\
\text { superficial. }\end{array}$ \\
\hline $\mathrm{P} 07$ & $4 \mathrm{~mm}$ & 22 & $\begin{array}{c}\text { Local da punção em AAD + } \\
\text { RF em } A D\end{array}$ & $\begin{array}{l}\text { AAD: perfuração com } \\
\text { trombose recente; } R F-A D \\
\text { trombose e necrose }\end{array}$ \\
\hline
\end{tabular}

* Potência média utilizada para atingir uma temperatura de 60 graus durante 60 segundos.

Legenda: $\mathrm{P}$ 01-07= porco 01 a $07, A E=$ átrio esquerdo, $A D=$ átrio direito, $\mathrm{AAD}=$ apêndice auricular direito, $\mathrm{AAE}=$ apêndice auricular esquerdo, $\mathrm{VCl}=$ veia cava inferior, $\mathrm{VCS}=$ veia cava superior, $\mathrm{VD}=$ ventrículo direito, $\mathrm{RF}=$ aplicação de radiofrequência, $\mathrm{TP}=$ tronco de artéria pulmonar. 


\section{ANEXO K: Características das aplicações de radiofrequência e dos achados histopatológicos (P08-P14):}

\begin{tabular}{|c|c|c|c|c|}
\hline ANIMAL & $\begin{array}{l}\text { Cateter } \\
\text { de RF }\end{array}$ & $\begin{array}{l}\text { Potência } \\
\text { (W) * }\end{array}$ & $\begin{array}{l}\text { Locais amostrados para } \\
\text { histologia }\end{array}$ & Histologia \\
\hline P08 & $8 \mathrm{~mm}$ & 28 & $\begin{array}{l}\text { Local da punção AAD } \\
\text { superior e inferior }\end{array}$ & $\begin{array}{l}\text { AAD: trombo na transição } \\
\text { entre o AD e a VCl, pertuito da } \\
\text { punção, trombo recente de } \\
\text { fibrina em toda a superfície } \\
\text { endocárdica. }\end{array}$ \\
\hline P09 & $\mathrm{N}$ & -- & $\begin{array}{l}\text { Local da punção em parede } \\
\text { posterior de } A D \text {, cortes } \\
\text { superior(S), posterior(P) e } \\
\text { inferior(I) }\end{array}$ & $\begin{array}{l}\text { ADS: trombo e necrose em } \\
\text { bandas de contração } \\
\text { adjacentes ao pertuito; } \\
\text { ADP:somente trombo; ADI: } \\
\text { trombo e um pouco de } \\
\text { necrose ao redor do orifício. }\end{array}$ \\
\hline P10 & $\mathrm{N}$ & -- & Local da punção de VD & $\begin{array}{c}\text { VD: pertuito com hemorragia } \mathrm{e} \\
\text { trombo }\end{array}$ \\
\hline $\mathrm{P} 11$ & $8 \mathrm{~mm}$ & 27 & $\begin{array}{l}\text { Local da punção AAD + } \\
\text { Locais de aplicação de RF } \\
\text { em AD posterior, lateral e } \\
\text { AAD inferior + } \\
\text { AE anterior }\end{array}$ & $\begin{array}{l}\text { AAD: trombo recente sem } \\
\text { perfuração amostrada } \\
\text { RF - AD: necrose recente e } \\
\text { extensa; AAD: lesão } \\
\text { transmural; AE: lesão do } \\
\text { epimural para médio-mural. }\end{array}$ \\
\hline $\mathrm{P} 12$ & $\mathrm{~N}$ & -- & $\begin{array}{l}\text { Local da punção AAD }{ }^{+} \\
\text {Prótese PREMERE }\end{array}$ & AAD:perfuração com trombo. \\
\hline $\mathrm{P} 13$ & $4 \mathrm{~mm}$ & 25 & $\begin{array}{l}\text { Local da punção AAD + } \\
\text { Locais de aplicação de RF } \\
\text { em AD lateral e posterior + } \\
\text { AE anterior e lateral }\end{array}$ & $\begin{array}{l}\text { AAD:perfuração com } \\
\text { trombo;; RF-AE: lesão em } \\
\text { banda de contração + } \\
\text { hemorragia no epicárdio; RF- } \\
\text { AD posterior: pericardite } \\
\text { fibrinosa com coronária livre; } \\
\text { RF-AD lateral: trombo } \\
\text { recente + lesão sub-endo- } \\
\text { miocárdica importante. }\end{array}$ \\
\hline
\end{tabular}

* Potência média utilizada para atingir uma temperatura de 60 graus durante 60 segundos.

Legenda: $\mathrm{P} 08-13=$ porco 08 a 13, $\mathrm{AE}=$ átrio esquerdo, $\mathrm{AD}=$ átrio direito, $\mathrm{AAD}=$ apêndice auricular direito, $\mathrm{AAE}=$ apêndice auricular esquerdo, $\mathrm{VD}=$ ventrículo direito, $\mathrm{RF}=$ aplicação de radiofrequência. 


\section{ANEXO L: Características das aplicações de radiofrequência e dos achados histopatológicos (P14-P20):}

\begin{tabular}{|c|c|c|c|c|}
\hline ANIMAL & $\begin{array}{l}\text { Cateter } \\
\text { de RF }\end{array}$ & $\begin{array}{l}\text { Potência } \\
\text { (W) * }\end{array}$ & $\begin{array}{l}\text { Locais amostrados } \\
\text { para histologia }\end{array}$ & Histologia \\
\hline P14 & $\begin{array}{l}4 \mathrm{~mm} \mathrm{e} \\
8 \mathrm{~mm}\end{array}$ & $\begin{array}{c}11 e \\
22\end{array}$ & $\begin{array}{c}\text { Local da punção } \\
\text { AAD + } \\
\text { Locais de aplicação } \\
\text { de RF em AD } \\
\text { posterior, lateral e } \\
\text { AAD inferior e anel + } \\
\text { AE anterior e TP }\end{array}$ & $\begin{array}{l}\text { AAD:trombo recente e foco de } \\
\text { necrose recente de cardiomiócitos ac } \\
\text { redor; RF-AD: trombo endocárdico } \\
\text { recente, miocitólise e eosinofilia nos } \\
\text { cardiomiócitos na metade } \\
\text { endocárdica adjacente ao trombo; } \\
\text { RF-AD: trombo recente, miocitólise } \\
\text { eosinofilia adjacente; RF-AE: necrose } \\
\text { em banda de contração no epicárdio } \\
\text { e trombo endocárdico. }\end{array}$ \\
\hline P15 & $8 \mathrm{~mm}$ & 30 & $\begin{array}{l}\text { Local da punção } \\
\text { AAD + } \\
\text { Locais de aplicação } \\
\text { de RF em AE } \\
\text { anterior + Prótese } \\
\text { PREMERE }\end{array}$ & $\begin{array}{l}\text { AAD:trombo aderido à prótese dos } \\
\text { dois lados; RF-AE:hemorragia e uma } \\
\text { lamina com trombo. }\end{array}$ \\
\hline P16 & $\mathrm{N}$ & -- & $\begin{array}{l}\text { Local da punção } \\
\qquad A A D\end{array}$ & $\begin{array}{l}\text { AAD: trombo recente sem perfuração } \\
\text { amostrada. }\end{array}$ \\
\hline P17 & $8 \mathrm{~mm}$ & 29 & $\begin{array}{c}\text { Local da punção VD } \\
+ \\
\text { Locais de aplicação } \\
\text { de RF em AD } \\
\text { posterior, lateral e } \\
\text { AE anterior e } \\
\text { posterior + Prótese } \\
\text { PREMERE }^{\text {TM }}\end{array}$ & $\begin{array}{c}\text { VD: perfuração com trombo; RF-AD: } \\
\text { lesão sub-endo sem lesão transmural } \\
\text { podendo se observar lesão no epi; } \\
\text { RF-AE ant: lesão epicárdica; RF-AE } \\
\text { post: lesão epicárdica até médio- } \\
\text { mural. }\end{array}$ \\
\hline P18 & $\mathrm{N}$ & -- & $\begin{array}{l}\text { Local da punção } \\
\text { AAD }\end{array}$ & $\begin{array}{c}\text { AAD: trombo recente sem perfuração } \\
\text { amostrada. }\end{array}$ \\
\hline P19 & $\mathrm{N}$ & -- & $\begin{array}{l}\text { Local da punção } \\
\text { AAD }\end{array}$ & $\begin{array}{l}\text { AAD: trombo sem perfuração } \\
\text { amostrada. }\end{array}$ \\
\hline P20 & $4 \mathrm{~mm}$ & 25 & $\begin{array}{c}\text { Local da punção } \\
\text { AAD + Locais de } \\
\text { aplicação de RF } \\
\text { em AD posterior, } \\
\text { lateral }\end{array}$ & $\begin{array}{l}\text { AAD: sem perfuração amostrada; } \\
\text { RF-AD post: ablação oblíqua, RF- } \\
\text { AD lat: transmural bem fino. }\end{array}$ \\
\hline
\end{tabular}

* Potência média utilizada para atingir uma temperatura de 60 graus durante 60 segundos.

Legenda: $\mathrm{P} 14-20=$ porco 14 a $20, \mathrm{AE}=$ átrio esquerdo, $\mathrm{AD}=$ átrio direito, $\mathrm{A} A \mathrm{D}=$ apêndice auricular direito, $\mathrm{VD}=$ ventrículo direito, $\mathrm{RF}=$ aplicação de radiofrequência, $\mathrm{TP}=$ tronco de artéria pulmonar. 
ANEXO M: Figura 10 - Fotografia da macroscopia do orifício no anel átrio-ventricular em seu aspecto epicárdico (a) e endocárdico (b).
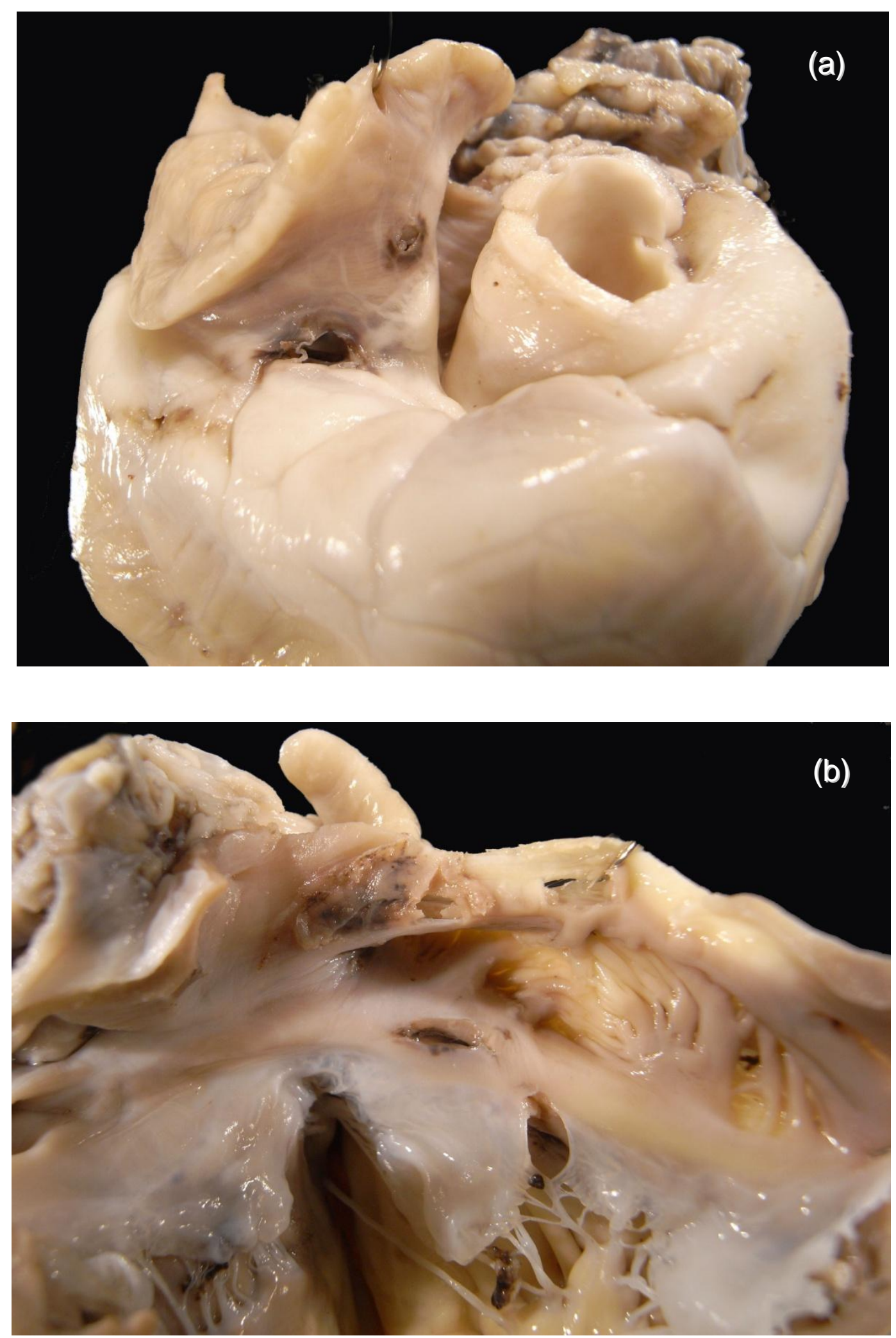
ANEXO N: Figura 11 - Fotografia da macroscopia da primeira âncora na face epicárdica do orifício atrial (a) e da segunda âncora na face endocárdica do orifício e visualização de trombo (b).
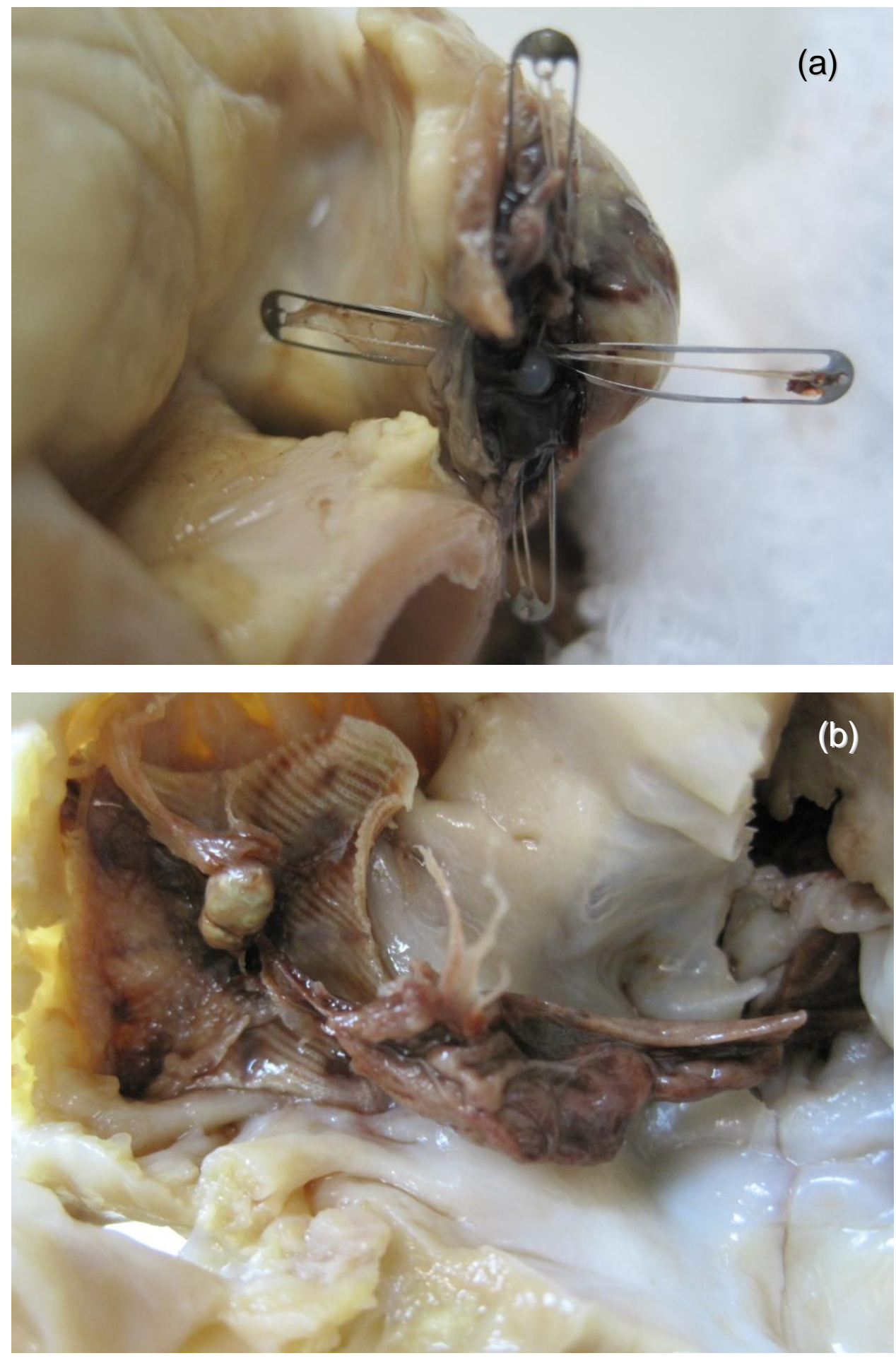
ANEXO O: Figura 12 - Fotografia da microscopia das lesões pela radiofrequência com visualização do trombo em cinco vezes de aumento (a) e de necrose em bandas de contração em dez vezes de aumento (b).
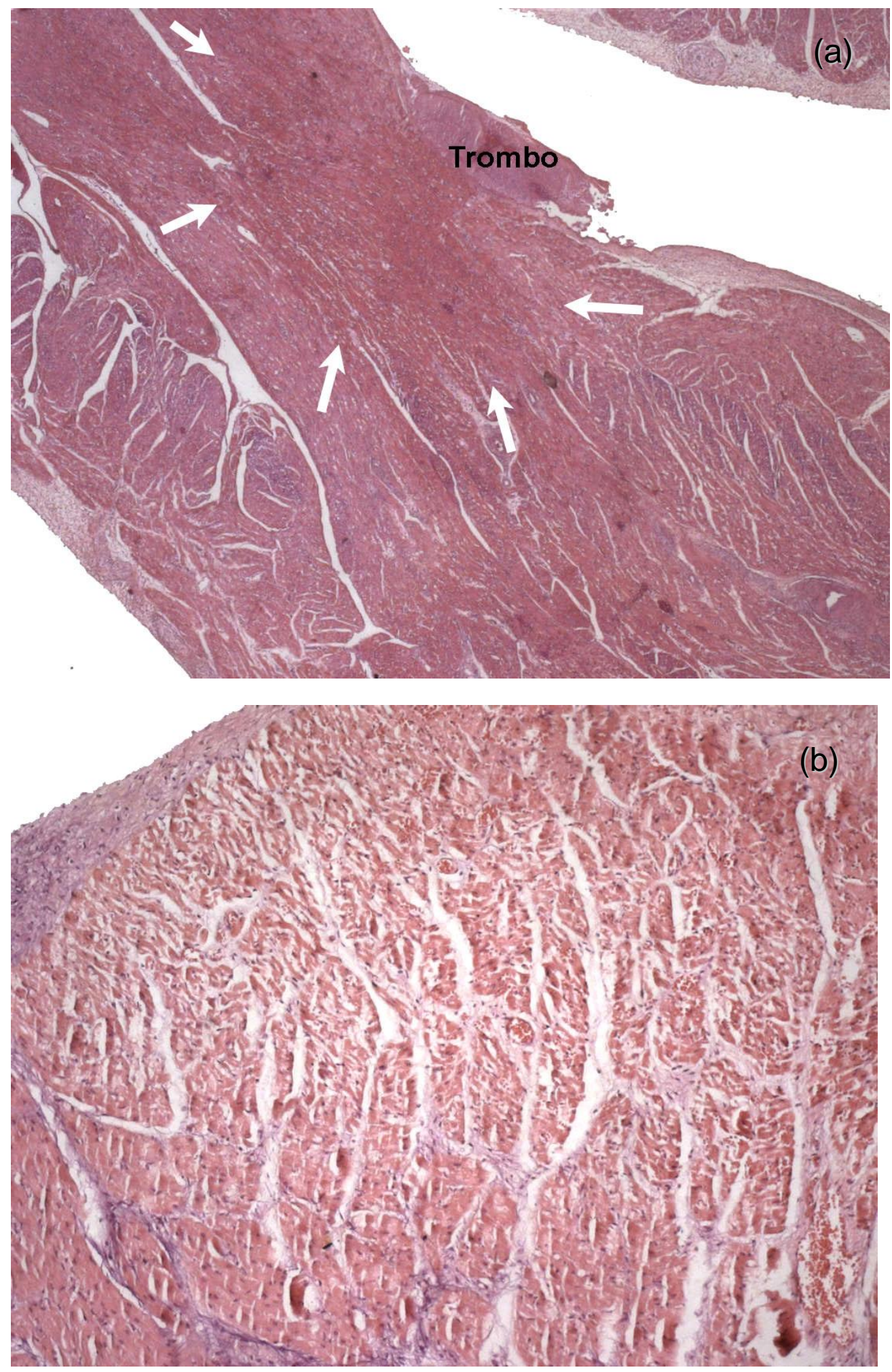


\section{REFERÊNCIAS BIBLIOGRÁFICAS}




\section{Referências bibliográficas}

1- Pritchett ELC. Management of atrial fibrillation. $N$ Engl $J$ Med. 1992;326:1264.

2- Morady F. Mechanisms and catheter ablation therapy of atrial fibrillation. Tex Heart Inst J. 2005;32(2):199-201.

3- HRS/EHRA/ECAS expert consensus statement on catheter and surgical ablation of atrial fibrillation: recommendations for personnel, policy, procedures and follow-up. A report of the Heart Rhythm Society (HRS) Task Force on Catheter and Surgical Ablation of Atrial Fibrillation developed in partnership with the European Heart Rhythm Association (EHRA) and the European Cardiac Arrhythmia Society (ECAS); in collaboration with the American College of Cardiology (ACC), American Heart Association (AHA), and the Society of Thoracic Surgeons (STS). Endorsed and approved by the governing bodies of the American College of Cardiology, the American Heart Association, the European Cardiac Arrhythmia Society, the European Heart Rhythm Association, the Society of Thoracic Surgeons, and the Heart Rhythm Society. Calkins H, Brugada J, Packer DL, Cappato R, Chen SA, Crijns HJ, Damiano RJ Jr, Davies DW, Haines DE, Haissaguerre $M$, lesaka $Y$, Jackman $W$, Jais $P$, Kottkamp H, Kuck KH, Lindsay BD, Marchlinski FE, McCarthy PM, Mont JL, Morady F, Nademanee K, Natale A, Pappone C, Prystowsky E, Raviele A, Ruskin JN, Shemin RJ; Heart Rhythm Society; European Heart Rhythm Association; European Cardiac Arrhythmia Society; American 
College of Cardiology; American Heart Association; Society of Thoracic Surgeons. Europace. 2007 Jun;9(6):335-79.

4- Thanassoulis G, Massaro JM, O'Donnell CJ, Hoffmann U, Levy D, Ellinor PT, Wang TJ, Schnabel RB, Vasan RS, Fox CS, Benjamin EJ. Pericardial Fat is Associated with Prevalent Atrial Fibrillation: The Framingham Heart Study. Circ Arrhythm Electrophysiol. 2010 Aug 1;3(4):345-50.

5- Haissaguerre M, Jaïs $\mathrm{P}$, Shah DC, et al. Spontaneous initiation of atrial fibrillation by ectopic beats originating in the pulmonary veins. $N$ Engl $J$ Med. 1998;339:659-66.

6- Chen PS, Maruyama M, Lin SF. Arrhythmogenic foci and the mechanisms of atrial fibrillation. Circ Arrhythm Electrophysiol. 2010 Feb 1;3(1):7-9.

7- Jaïs P, Shah DC, Haïssaguerre M, Hocini M, Garrigue S, Clémenty J. Atrial fibrillation: role of arrhythmogenic foci. $J$ Interv Card Electrophysiol. 2000 Jan;4 Suppl 1:29-37.

8- Nademanee K, McKenzie J, Kosar E. A new approach for catheter ablation of atrial fibrillation: mapping of the electrophysiologic substrate. $J$ Am Coll Cardiol. 2004 Jun 2;43(11):2044-53.

9- Pachón M JC, Pachón M El, Pachón M JC. A new treatment for atrial fibrillation based on spectral analysis to guide the catheter RF-ablation. Europace. 2004;6(6):590-601.

10-Nakagawa JA, Scherlag BJ, Wu R. Addition of selective ablation of autonomic ganglia to pulmonary vein antrum isolation for treatment of paroxysmal and persitent atrial fibrillation. Circulation. 2004;110:17(III543) 2531. 
11-Pappone C, Santinelli V, Manguso F. Pulmonary vein denervation enhances long-term benefit after circumferential ablation for paroxysmal atrial fibrillation. Circulation. 2004;109:327-34.

12-Katritsis D, loannidis JP, Anagnostopoulos CE, Sarris GE, Giazitzoglou E, Korovesis S, Camm AJ. Identification and catheter ablation of extracardiac and intracardiac components of ligament of Marshall tissue for treatment of paroxysmal atrial fibrillation. J Cardiovasc Electrophysiol. $2001 \mathrm{Jul} ; 12(7): 750-8$.

13-Reddy VY, Neuzil P, D'Avila A, Ruskin JN. Isolating the posterior left atrium and pulmonary veins with a "box" lesion set: use of epicardial ablation to complete electrical isolation. J Cardiovasc Electrophysiol. 2008 Mar;19(3):326-9.

14-Scherlag BJ, Nakagawa H, Jackman WM, Yamanashi WS, Patterson E, Po S, Lazzara R. Electrical stimulation to identify neural elements on the heart: their role in atrial fibrillation. J Interv Card Electrophysiol. 2005 Aug;13 Suppl 1:37-42.

15-Scanavacca M, Pisani CF, Hachul D, Lara S, Hardy C, Darrieux F, Trombetta I, Negrão CE, Sosa E. Selective atrial vagal denervation guided by evoked vagal reflex to treat patients with paroxysmal atrial fibrillation. Circulation. 2006 Aug 29;114(9):876-85.

16-Pokushalov E, Romanov A, Shugayev P, Artyomenko S, Shirokova N, Turov A, Katritsis DG. Selective ganglionated plexi ablation for paroxysmal atrial fibrillation. Heart Rhythm. 2009 Sep;6(9):1257-64.

17-Katritsis D, Giazitzoglou E, Sougiannis D, Goumas N, Paxinos G, Camm 
AJ. Anatomic approach for ganglionic plexi ablation in patients with paroxysmal atrial fibrillation. Am J Cardiol. 2008 Aug 1;102(3):330-4.

18-Schweikert RA, Saliba WI, Tomassoni G, Marrouche NF, Cole CR, Dresing TJ, Tchou PJ, Bash D, Beheiry S, Lam C, Kanagaratnam L, Natale A. Percutaneous pericardial instrumentation for endo-epicardial mapping of previously failed ablations. Circulation. 2003;108(11):132935.

19-Stewart S, Hart CL, Hole DJ, McMurray JJ. A population-based study of the long-term risks associated with atrial fibrillation: 20-year follow-up of the Renfrew/Paisley study. Am J Med. 2002;113:359-364.

20-Pappone C, Santinelli V. The Who, What, Why, and How - To Guide for Circumferential Pulmonary Vein Ablation. J Cardiovasc Electrophysiol. 2004;1226-30.

21-Marrouche NF, Dresing T, Cole C. Circular mapping and ablation of the pulmonary vein for treatment of atrial fibrillation: impact of different catheter technologies. J Am Coll Cardiol. 2002;40(3):464-74.

22-Cappato R, Calkins H, Chen SA, Davies W, lesaka Y, Kalman J, Kim YH, Klein G, Packer D, Skanes A. Worldwide survey on the methods, efficacy and safety of catheter ablation for human atrial fibrillation. Circulation. 2005;9:1100-5.

23-Pappone C, Santinelli V. Atrial fibrillation ablation: state of the art. $A m \mathrm{~J}$ Cardiol. 2005 Dec 19;96(12A):59L-64L.

24-Fuster V, Ryden LE, Cannom DS, Crijns HJ, Curtis AB, Ellenbogen KA, Halperin JL, Le Heuzey JY, Kay GN, Lowe JE, Olsson SB, Prystowsky 
EN, Tamargo JL, Wann S, Smith SCJ, Jacobs AK, Adams CD, Anderson JL, Antman EM, Halperin JL, Hunt SA, Nishimura R, Ornato JP, Page RL, Riegel B, Priori SG, Blanc JJ, Budaj A, Camm AJ, Dean V, Deckers JW, Despres C, Dickstein K, Lekakis J, McGregor K, Metra M, Morais J, Osterspey A, Tamargo JL, Zamorano JL. ACC/AHA/ESC 2006 Guidelines for the Management of Patients With Atrial Fibrillation: A report of the American College of Cardiology/American Heart Association Task Force on Practice Guidelines and the European Society of Cardiology Committee for Practice Guidelines (Writing Committee to Revise the 2001 Guidelines for the Management of Patients With Atrial Fibrillation): Developed in collaboration with the European Heart Rhythm Association and the Heart Rhythm Society. Circulation. 2006;114:e257-e354.

25-Scanavacca MI, de Brito FS, Maia I, Hachul D, Gizzi J, Lorga A, Rassi A Jr, Filho MM, Mateos JC, D'Avila A, Sosa E. Guidelines for the evaluation and treatment of patients with cardiac arrhythmias. Sociedade Brasileira de Cardiologia. Arq Bras Cardiol. 2002;79 Suppl 5:1-50.

26-The AFFIRM Investigators: A comparison of rate control and rhythm control in patients with atrial fibrillation. N Engl J Med. 2002;347:1825-33.

27-Carlsson J Miketic S, Windeler J, et al. Randomized trial of rate control versus rhythm control in persistent atrial fibrillation: the strategies of treatment of atrial fibrillation (STAF) study. $J$ Am Coll Cardiol. 2003;41:1690-6.

28- Jais $P$, Haissaguerre $M$, Shah DC. A focal source of atrial fibrillation treated by discrete radiofrequency ablation. Circulation. 1997;95:572-6. 
29- Chen SA, Hsieh MH, Tai CT, et al. Initiation of atrial fibrillation by ectopic beats originating from the pulmonary veins: electrophysiological characteristics, pharmacological responses, and effects of radiofrequency ablation. Circulation. 1999;100(18):1879-86.

30- Lin Ws, Tai CT, Hsieh MH, et al. Catheter ablation of paroxysmal atrial fibrillation initiated by non-pulmonary vein ectopy. Circulation. 2003;107:3176-83.

31-Scanavacca M, Sartini R, Tondato F, Hachul D, Lara S, Hardy C, Darrieux F, Sosa E. Pulmonary veins isolation to treat patients with refractory paroxysmal atrial fibrillation: clinical results after a single procedure. Arq Bras Cardiol. 2004;82(2):160-4,155-9.

32-Hocini M, Sanders P, Jaïs P, Hsu L-F, Takahashi Y, Rotter M, Clémenty J, Haïssaguerre M. Techniques for curative treatment of atrial fibrillation. $J$ Cardiovasc Electrophysiol. 2004;15(12):1467-71.

33-Bhargava M, Marrouche NF, Martin D, Themistoclakis S, Stewart K, Saliba WI, Schweikert RA, Natale A. Impact of Age on the Outcome of Pulmonary Vein Isolation for Atrial Fibrillation Using Circular Mapping Technique and Cooled-Tip Ablation Catheter: A Retrospective Analysis. $J$ Cardiovasc Electrophysiol. 2004;15:8-13.

34-Bhargava M, Di Biase L, Mohanty P, Prasad S, Martin DO, WilliamsAndrews M, Wazni OM, Burkhardt JD, Cummings JE, Khaykin Y, Verma A, Hao S, Beheiry S, Hongo R, Rossillo A, Raviele A, Bonso A, Themistoclakis S, Stewart K, Saliba WI, Schweikert RA, Natale A. Impact of type of atrial fibrillation and repeat catheter ablation on long-term 
freedom from atrial fibrillation: results from a multicenter study. Heart Rhythm. 2009 Oct;6(10):1403-12.

35-Sartini RJ, Scanavacca MI, Sosa E, Moreira LF, Lara S, Hardy C, Darrieux F, Hachul D. Radiofrequency ablation of paroxysmal atrial fibrillation: factors determining long-term clinical efficacy. Arq Bras Cardiol. 2008 Feb;90(2):112-8.

36-Haissaguerre $M$, Jais $P$, Shah DC, et al. Electrophysiological end point for catheter ablation of atrial fibrillation initiated from multiple pulmonary venous foci. Circulation. 2000;101:1409-17.

37-Voeller RK, Bailey MS, Zierer A, Lall SC, Sakamoto S, Aubuchon K, Lawton JS, Moazami N, Huddleston CB, Munfakh NA, Moon MR, Schuessler RB, Damiano RJ Jr. Isolating the entire posterior left atrium improves surgical outcomes after the Cox maze procedure. J Thorac Cardiovasc Surg. 2008 Apr;135(4):870-7.

38-Melby SJ, Lee AM, Zierer A, Kaiser SP, Livhits MJ, Boineau JP, Schuessler RB, Damiano RJ Jr. Atrial fibrillation propagates through gaps in ablation lines: implications for ablative treatment of atrial fibrillation. Heart Rhythm. 2008 Sep;5(9):1296-1301.

39-Melby SJ, Zierer A, Bailey MS, Cox JL, Lawton JS, Munfakh N, Crabtree TD, Moazami N, Huddleston CB, Moon MR, Damiano RJ Jr. A new era in the surgical treatment of atrial fibrillation: the impact of ablation technology and lesion set on procedural efficacy. Ann Surg. 2006 Oct;244(4):583-92.

40-Pappone C, Oreto G, Lamberti F et al. Catheter ablation of paroxysmal 
atrial fibrillation using a 3-D mapping system. Circulation. 1999;14:1203-8. 41-Rahmanian PB, Castillo JG, Mehta D, Adams DH, Filsoufi F. Epicardial pulmonary vein isolation: a long-term histologic and imaging animal study comparing cryothermy versus radiofrequency. Ann Thorac Surg. 2008 Sep;86(3):849-56 .

42-Miyagi Y, Ishii Y, Nitta T, Ochi M, Shimizu K. Electrophysiological and histological assessment of transmurality after epicardial ablation using unipolar radiofrequency energy. J Card Surg. 2009 Jan-Feb;24(1):34-40. 43-Pak HN, Hwang C, Lim HE, Kim JS, Kim YH. Hybrid epicardial and endocardial ablation of persistent or permanent atrial fibrillation: a new approach for difficult cases. J Cardiovasc Electrophysiol. 2007 Sep;18(9):917-23.

44-Jais $\mathrm{P}$, Hocini M, Hsu LF et al. Technique and results of linear ablation at the mitral isthmus. Circulation. 2004;110:2996-3002.

45-Pappone C, Santinelli V. How to perform encircling ablation of the left atrium. Heart Rhythm. 2006;9:1105-9.

46-Rostock T, Willems S. Rhythm-'a-line-ment' during catheter ablation of chronic atrial fibrillation: the role of left atrial linear lesions. Eur Heart $\mathrm{J}$. 2008 Oct; 29(19):2321-2.

47-Knecht S, Hocini M, Wright M, Lellouche N, O'Neill MD, Matsuo S, Nault I, Chauhan VS, Makati KJ, Bevilacqua M, Lim KT, Sacher F, Deplagne A, Derval N, Bordachar P, Jaïs P, Clémenty J, Haïssaguerre M. Left atrial linear lesions are required for successful treatment of persistent atrial fibrillation. Eur Heart J. 2008 Oct;29(19):2359-66. 
48-Fenelon G, Scanavacca M, Atié J, Zimerman L, Magalhães LP, Lorga Filho A, Maia H, Martinelli Filho M; Brazilian Society of Cardiac Arrhythmias. Atrial fibrillation ablation in Brazil: results of the registry of the Brazilian Society of Cardiac Arrhythmias. Arq Bras Cardiol. 2007 Nov;89(5):258-62,285-9.

49-Oral H, Scharf $\mathrm{C}$, Chugh A et al. Catheter ablation for paroxysmal atrial fibrillation: segmental pulmonary vein ostial ablation versus left atrial ablation. Circulation. 2003;108(19):2355-60.

50-Papone C, Rosanio S, Oreto G, et al. Circumferencial radiofrequency ablation of pulmonary vein ostia: a new anatomic approach for curing atrial fibrillation. Circulation. 2000;102:2619-28.

51-Smelley MP, Knight BP. Approaches to catheter ablation of persistent atrial fibrillation. Heart Rhythm. 2009 Aug:6(8 Suppl):S33-S38.

52-Reddy VY, Neuzil P, Themistoclakis S, Danik SB, Bonso A, Rossillo A, Raviele A, Schweikert R, Ernst S, Kuck KH, Natale A. Visually-guided balloon catheter ablation of atrial fibrillation: experimental feasibility and first-in-human multicenter clinical outcome. Circulation. 2009 Jul $7 ; 120(1): 12-20$

53-Hsu LF, Jais P, Hocini M, Sanders P, Scavee C, Sacher F, Takahashi Y, Rotter M, Pasquie JL, Clementy J, Haissaguerre M. Incidence and prevention of cardiac tamponade complicating ablation for atrial fibrillation. Pacing Clin Electrophysiol. 2005 Jan;28 Suppl 1:S106-S109.

54-Bunch TJ, Asirvatham SJ, Friedman PA, Monahan KH, Munger TM, Rea RF, Sinak LJ, Packer DL. Outcomes after cardiac perforation during 
radiofrequency ablation of the atrium. J Cardiovasc Electrophysiol. 2005;11:1172-9.

55-Cappato R, Calkins H, Chen SA, Davies W, lesaka Y, Kalman J, Kim YH, Klein G, Natale A, Packer D, Skanes A. Prevalence and causes of fatal outcome in catheter ablation of atrial fibrillation. J Am Coll Cardiol. 2009 May 12;53(19):1798-1803.

56-O'Neill MD, Jaïs P, Derval N, Hocini M, Haïssaguerre M. Two techniques to avoid surgery for cardiac tamponade occurring during catheter ablation of atrial fibrillation. J Cardiovasc Electrophysiol. 2008 Mar;19(3):323-325.

57-Dagres N, Varounis C, Flevari P, Piorkowski C, Bode K, Rallidis LS, Tsougos E, Leftheriotis D, Sommer P, Hindricks G, Kremastinos DT. Mortality after catheter ablation for atrial fibrillation compared with antiarrhythmic drug therapy. A meta-analysis of randomized trials. Am Heart J. 2009 Jul;158(1):15-20.

58-Krikorian JG, Hancock EW. Pericardiocentesis. Am J Med. 1978 Nov;65(5):808-14 .

59-Fisher JD, Kim SG, Ferrick KJ, Gross JN, Goldberger MH, Nanna M. Internal transcardiac pericardiocentesis for acute tamponade. $A m \mathrm{~J}$ Cardiol. 2000 Dec 15;86(12):1388-1389, A6.

60-Hsu LF, Jais P, Hocini et al. Incidence and prevention of cardiac tamponade complicating ablation for atrial fibrillation. Pacing Elin electrophysiol. 2005;28:S106-9.

61-Hsu LF, Scavée C, Jaïs P, Hocini M, Haïssaguerre M. Transcardiac pericardiocentesis: an emergency life-saving technique for cardiac 
tamponade. J Cardiovasc Electrophysiol. 2003 Sep;14(9):1001-3.

62-Sacher F, Roberts-Thomson K, Maury P, Tedrow U, Nault I, Steven D, Hocini M, Koplan B, Leroux L, Derval N, Seiler J, Wright MJ, Epstein L, Haissaguerre M, Jais P, Stevenson WG. Epicardial ventricular tachycardia ablation a multicenter safety study. J Am Coll Cardiol. 2010 May 25;55(21):2366-72.

63-Soejima K, Stevenson WG, Sapp JL, Selwyn AP, Couper G, Epstein LM. Endocardial and epicardial radiofrequency ablation of ventricular tachycardia associated with dilated cardiomyopathy: the importance of low-voltage scars. J Am Coll Cardiol. 2004;43(10):1834-42.

64-De Paola AA, Melo WD, Távora MZ, Martinez EE. Angiographic and electrophysiological substrates for ventricular tachycardia mapping through the coronary veins. Heart. 1998 Jan;79(1):59-63.

65-Sosa E, Scanavacca M, D'Avila A, Bellotti G, Pilleggi F. Radiofrequency catheter ablation of ventricular tachycardia guided by nonsurgical epicardial mapping in chronic Chagasic heart disease. Pacing Clin Electrophysiol. 1999 Jan; 22(1 Pt 1):128-30.

66-Sosa E, Scanavacca M, D'Avila A, Pilleggi F. A new technique to perform epicardial mapping in the electrophysiology laboratory. J Cardiovasc Electrophysiol. 1996 Jun;7(6):531-6.

67-Sosa E, Scanavacca M, D'Avila A, Piccioni J, Sanchez O, Velarde JL, Silva M, Reolão B. Endocardial and epicardial ablation guided by nonsurgical transthoracic epicardial mapping to treat recurrent ventricular tachycardia. J Cardiovasc Electrophysiol. 1998 Mar;9(3):229-39. 
68-Sosa E, Scanavacca M, D'Avila A, Oliveira F, Ramires JA. Nonsurgical transthoracic epicardial catheter ablation to treat recurrent ventricular tachycardia occurring late after myocardial infarction. J Am Coll Cardiol. 2000 May; 35(6):1442-9.

69-Sosa E, Scanavacca M, D'Avila A, Antônio J, Ramires F. Nonsurgical transthoracic epicardial approach in patients with ventricular tachycardia and previous cardiac surgery. J Interv Card Electrophysiol. 2004 Jun;10(3):281-8.

70-D'Avila A, Scanavacca M, Sosa E. Transthoracic epicardial catheter ablation of ventricular tachycardia. Heart Rhythm. 2006 Sep;3(9):1110-1.

71-D'Avila A. Epicardial catheter ablation of ventricular tachycardia. Heart Rhythm. 2008 Jun;5(6 Suppl):S73-S75.

72-Weerasooriya R, Jais P, Sacher F, Knecht S, Wright M, Lellouch N, Nault I, Matsuo S, Hocini M, Clementy J, Haissaguerre M. Utility of the lateral fluoroscopic view for subxiphoid pericardial access. Circ Arrhythm Electrophysiol. 2009 Aug;2(4):e15-7.

73-Verrier RL, Waxman S, Lovett EG, Moreno R. Transatrial access to the normal pericardial space: a novel approach for diagnostic sampling, pericardiocentesis, and therapeutic interventions. Circulation. 1998 Nov $24 ; 98(21): 2331-2333$.

74-Pulerwitz TC, Waxman S, Rowe KA, Quist WC, Lipinska I, Verrier RL. Transatrial access to the normal pericardial space for local cardiac therapy: preclinical safety testing with aspirin and pulmonary artery hypertension. J Interv Cardiol. 2001 Oct;14(5):493-498. 
75-Waxman S, Pulerwitz TC, Rowe KA, Quist WC, Verrier RL. Preclinical safety testing of percutaneous transatrial access to the normal pericardial space for local cardiac drug delivery and diagnostic sampling. Catheter Cardiovasc Interv. 2000 Apr;49(4):472-7.

76-Waxman S, Moreno R, Rowe KA, Verrier RL. Persistent primary coronary dilation induced by transatrial delivery of nitroglycerin into the pericardial space: a novel approach for local cardiac drug delivery. J Am Coll Cardiol. 1999;33(7):2073-7.

77-Bolderman RW, Hermans JJ, Rademakers LM, Jansen TS, Verheule S, van der Veen FH, Maessen JG. Intrapericardial delivery of amiodarone and sotalol: atrial transmural drug distribution and electrophysiological effects. J Cardiovasc Pharmacol. 2009 Oct;54(4):355-63.

78-Mickelsen SR, Ashikaga H, Desilva R, Raval AN, McVeigh E, Kusumoto F. Transvenous access to the pericardial space: an approach to epicardial lead implantation for cardiac resynchronization therapy. Pacing Clin Electrophysiol. 2005 Oct;28(10):1018-24.

79-Kassab G S, Svendsen M, Combs W. A transatrial pericardial access: lead placement as proof of concept. Am J Physiol Heart Circ Physiol. 2010;298(1):H287-93.

80-Byrd CL, Schwartz SJ. Transatrial implantation of transvenous pacing leads as an alternative to implantation of epicardial leads. Pacing Clin Electrophysiol. 1990 Dec;13(12 Pt 2):1856-9. 
81-Scanavacca M, Pisani CF, Lara S, Sosa E. Management of posterior atrial wall perforation during transeptal approach for left atrium ablation. Heart Rhythm. 2009 Aug;6(8):1222-5.

82-Masura J, Walsh KP, Thanopoulous B, Chan C, Bass J, Goussous Y, Gavora P, Hijazi ZM. Catheter closure of moderate- to large-sized patent ductus arteriosus using the new Amplatzer duct occluder: immediate and short-term results. J Am Coll Cardiol. 1998 Mar 15;31(4):878-82.

83-Thanopoulos BD, Tsaousis GS, Konstadopoulou GN, Zarayelyan AG. Transcatheter closure of muscular ventricular septal defects with the amplatzer ventricular septal defect occluder: initial clinical applications in children. J Am Coll Cardiol. 1999 Apr;33(5):1395-9.

84-McMahon CJ, El Said HG, Mullins CE. Use of the transeptal puncture in transcatheter closure of long tunnel-type patent foramen ovale. Heart. 2002 Aug;88(2):E3.

85-Hildick-Smith D, Behan M, Haworth P, Rana B, Thomas M. Patent foramen ovale closure without echocardiographic control: use of "standby" intracardiac ultrasound. JACC Cardiovasc Interv. 2008 Aug;1(4):387-91.

86-Büscheck F, Sievert H, Kleber F, Tiefenbacher C, Krumsdorf U, Windecker S, Uhlemann F, Wahr DW. Patent foramen ovale using the Premere device: the results of the CLOSE-UP trial. J Interv Cardiol. 2006 Aug;19(4):328-33. 
87-Rastogi N, Smeeton NC, Qureshi SA. Factors related to successful transcatheter closure of atrial septal defects using the Amplatzer septal occluder. Pediatr Cardiol. 2009 Oct;30(7):888-92.

88-Wahl A, Tai T, Praz F, Schwerzmann M, Seiler C, Nedeltchev K, Windecker S, Mattle HP, Meier B. Late results after percutaneous closure of patent foramen ovale for secondary prevention of paradoxical embolism using the amplatzer PFO occluder without intraprocedural echocardiography: effect of device size. JACC Cardiovasc Interv. 2009 Feb;2(2):116-23.

89-Geovanini GR, Pinna FR, Prado FA, Tamaki WT, Marques E. Standardization of anesthesia in swine for experimental cardiovascular surgeries. Rev Bras Anestesiol. 2008 Jul-Aug;58(4):363-70.

90-Elinav E, Leibowitz D. Constrictive pericarditis complicating endovascular pacemaker implantation. Pacing Clin Electrophysiol. 2002;25(3):376-7.

91-D’Avila A, Neuzil P, Thiagalingam A. Experimental Efficacy of Pericardial Instillation of anti-inflammatory agents during percutaneous epicardial catheter ablation to prevent post procedure pericarditis. J Cardiovasc Electrophysiol. 2007;18(11):1178-83. 